\title{
Activation of the Wnt- $\beta$ Catenin Pathway in a Cell Population on the Surface of the Forebrain Is Essential for the Establishment of Olfactory Axon Connections
}

\author{
Ambra A. Zaghetto, ${ }^{1}$ Sara Paina, ${ }^{1}$ Stefano Mantero, ${ }^{1}$ Natalia Platonova, ${ }^{1}$ Paolo Peretto, ${ }^{2}$ Serena Bovetti, ${ }^{2,3}$ Adam Puche, ${ }^{3}$ \\ Stefano Piccolo, ${ }^{4}$ and Giorgio R. Merlo ${ }^{1}$ \\ ${ }^{1}$ Dulbecco Telethon Institute-Consiglio Nazionale delle Ricerche Institute for Biomedical Technologies Milano, 20090 Segrate, Italy, ${ }^{2}$ Department of Animal \\ and Human Biology, University of Torino, 10123 Torino, Italy, ${ }^{3}$ Department of Anatomy and Neurobiology, School of Medicine, University of Maryland, \\ Baltimore, Maryland 21201, and ${ }^{4}$ Department of Histology, Microbiology, and Medical Biotechnologies, School of Medicine, University of Padova, 35122 \\ Padova, Italy
}

\begin{abstract}
A variety of signals governing early extension, guidance, and connectivity of olfactory receptor neuron (ORN) axons has been identified; however, little is known about axon-mesoderm and forebrain (FB)-mesoderm signals. Using Wnt- $\beta$ catenin reporter mice, we identify a novel Wnt-responsive resident cell population, located in a Frizzled7 expression domain at the surface of the embryonic FB, along the trajectory of incoming ORN axons. Organotypic slice cultures that recapitulate olfactory-associated Wnt- $\beta$ catenin activation show that the $\beta$ catenin response depends on a placode-derived signal(s). Likewise, in $D l x 5-1-$ embryos, in which the primary connections fail to form, Wnt- $\beta$ catenin response on the surface of the FB is strongly reduced. The olfactory placode expresses a number of $\beta$ cateninactivating Wnt genes, and the Frizzled7 receptor transduces the "canonical" Wnt signal; using Wnt expression plasmids we show that Wnt5a and Wnt7b are sufficient to rescue $\beta$ catenin activation in the absence of incoming axons. Finally, blocking the canonical Wnt pathway with the exogenous application of the antagonists Dikkopf-1 or secreted-Frizzled-receptor protein-2 prevents ORN axon contact to the FB. These data reveal a novel function for Wnt signaling in the establishment of periphery-CNS olfactory connections and highlight a complex interplay between cells of different embryonic origin for ORN axon connectivity.
\end{abstract}

Key words: Wnt; Frizzled; $\beta$ catenin; olfactory; axon; connectivity

\section{Introduction}

During development of the olfactory pathway, a number of processes occur that coordinate axon guidance and connectivity (Scott and Brirley, 1999; Bozza et al., 2002; Brunjes and Greer, 2003). Beginning at embryonic day 10 (E10), immature olfactory receptor neurons (ORNs) in the olfactory placode (OP) extend axons toward the forebrain (FB) along with several populations of migratory cells (Gong and Shipley, 1996). This meshwork of

\footnotetext{
Received 0ct. 10, 2006; revised June 29, 2007; accepted July 4, 2007.

G.R.M. is the recipient of a Telethon Career Award (TCP99003) and was supported by Fondazione Cariplo (20052007) and Fondazione San Paolo (2005, 2007 (Dulbecco Telethan Institute). A.A.Z. is in the Doctorate Program of the Department of Comparative Anatomy at the University of Milano. S.Pa. was supported by Ingenio (Italy). S.Pi. was supported by Telethon-Italy. A.P. was supported by National Institutes of Health-National Institute on Deafness and Other Communication Disorders Grant DC05739. P.P. was supported by Fondazione San Paolo $(2004,2019)$ and CIPE Reg. Piemonte (2004, A14). We thank Dr. A. McMahon (Harvard University, Boston, MA), Dr. S. Pleasure (University of California San Francisco, San Francisco, CA), Dr. R. Nusse (Stanford University, Stanford, CA), and Dr. L. Muzio (DiBit-San Raffaele, Milan, Italy) for probes. We thank Dr. Y. Zou (University of California San Diego, La Jolla, CA) for the Wnt-myc expression plasmids. We are indebted to Dr. K. Tucker (Center of Neuroscience, University of Heidelberg, Heidelberg, Germany) for the tau-eGFP mice, to Prof. U. Fascio (CIMA, University of Milano, Milano, Italy) for confocal microscopy, and to Drs. S. Bertuzzi and H. Arnheiter (National Institute of Neurological Disorders and Stroke, Bethesda, MD) for helpful criticism.

Correspondence should be addressed to Dr. Giorgio R. Merlo, Dulbecco Telethon Institute-Consiglio Nazionale delle Ricerche Institute for Biomedical Technologies, Via F.lli Cervi 93, 20090 Segrate (Milan), Italy. E-mail: gmerlo@dti.telethon.it.

DOI:10.1523/JNEUROSCI.0763-07.2007

Copyright $\odot 2007$ Society for Neuroscience $\quad$ 0270-6474/07/279757-12\$15.00/0
}

neurites and migratory cells form a migratory mass (MM) that remains separated from the $\mathrm{FB}$ by the basement membrane (BM). A small number of pioneer axons enter the FB at earlier stages (Fueshko and Wray, 1994; Key, 1998; Astic et al., 2002), but their function is still unclear. At E14.5, the BM reorganizes and ORN axons enter the FB to form the outer sublaminae of the nerve layer (Doucette, 1989; Bailey et al., 1999; Au et al., 2002).

This organization results from sequential interactions between growing axons and their environment (Key, 1998; Lin and Ngai, 1999; Brunjes and Greer, 2003). Numerous signals and cell populations, of both placodal and mesenchymal origin, are known to participate, such as the chemoattractant Netrin 1 (Astic et al., 2002), semaphorins/neuropilins (Williams-Hogarth et al., 2000), Eph/Ephrins (Gao et al., 2000), Slit/Robo (Li et al., 1999), neural cell adhesion molecule (NCAM) (Treloar et al., 1997), Galectin1 (Puche et al., 1996), and p75 NGF receptor (Tisay et al., 2000). Retinoic acid, FGF8, sonic hedgehog, and bone morphogenetic proteins have been shown to mediate mesenchymal-OP interactions and initiate neurite outgrowth (LaMantia et al., 2000; Bashin et al., 2003). However, little is known about signals that mediate neurite-mesenchyme and mesenchyma-FB interactions, essential for connectivity. Their importance for axon-mesenchyme-FB interactions is highlighted by the phenotype of Kallmann patients, in which olfactory axons-olfactory bulb 
(OB) connections and the migration of gonadotropin-releasing hormone $(\mathrm{GnRH})$ cells are compromised (Rugarli et al., 1996; Dode and Hardelin, 2004; Gonzàlez-Martinez et al., 2004). We (Levi et al., 2003) and others (Long et al., 2003) have reported a Kallmann-like phenotype in Dlx5-1- mice: ORNs extend axons, but these fail to contact the OB.

Wnt proteins are a family of morphogens involved in several key developmental processes (Logan and Nusse, 2004) and recently have been shown to have guidance functions for CNS axons (Lyuksyutova et al., 2003; Liu et al., 2005); however, little is known about their role in axonal connectivity. Because of the complexity of the Wnt signaling and its transduction pathways, an in vivo Wnt readout (BAT ${ }^{\text {nlac }}$ mice) has been devised: activation of a Wnt-dependent $\beta$ catenin "canonical" pathway (Maretto et al., 2003; Widelitz, 2005; Willert and Jones, 2006) can be visualized by the presence of nuclear $\beta$ galactosidase ( $\beta$ gal) in target cells. We have used these reporter mice to examine the role of Wnt signaling in early olfactory assembly. We have identified a Wnt-responsive cell population located at the interface of the BM and the FB, expressing the Frizzled7 receptor gene. Incoming axons are required for $\beta$ catenin activation, and we show that $W n t 5 a$ and $W n t 7 b$ are sufficient to replace them. We also show that $\beta$ catenin activation is required for the ability of axons to form connections with the FB, a novel function for this family of morphogens.

\section{Materials and Methods}

Mouse strains and breeding. The Wnt reporter mice denominated BAT ${ }^{\text {nlac } Z}$ contain the nucleus-targeted lac $Z$ reporter sequence expressed from a promoter containing seven copies of a $\beta$ catenin-lymphoid enhancer factor/T cell factor-responsive site (Maretto et al., 2003). These transgenic animals were maintained and used as a heterozygous $(+/-)$ strain. Mice with targeted disruption of $D l x 5$ have been reported previously (Acampora et al., 1999). BAT ${ }^{\text {nlacZ }}$ mice were crossed with $D l x 5+/-$ mice to obtain double-heterozygous ones. From crossbreeding these with Dlx5+1- mates, embryos with genotype Dlx5-/-;BAT ${ }^{\text {nlacz }}$ were obtained at the expected frequency $(12.5 \%)$. To visualize the ORN axons in cultured slices, tau-eGFP mice were used (Tucker et al., 2001), in which the enhanced green fluorescent protein $(e G F P) \mathrm{cDNA}$ was targeted to the tau locus [a microtubule-associated protein present in all axonal extensions (Binder et al., 1985)]. Fluorescence was readily observed in early olfactory neurites. $\beta$-actin-eGFP mice were used as donors in grafting experiments (Okabe et al., 1997). Both eGFP transgenic strains were maintained and used as heterozygous. $\beta$-actin-eGFP mice were crossed with $D l x 5+1-$ mates to obtain double heterozygous. By crossing these with $D l \times 5+/-$ mates, Dlx5-1-;eGFP+ embryos were obtained at the expected frequency. The Institutional Animal Care Committee and the Ministry of Health approved all the animal procedures used.

Sample collection and histochemistry. Embryos were collected between 11.5 and $14.5 \mathrm{~d}$ of gestation by cesarean section, or at birth (postnatal day 0 ), fixed in $4 \%$ paraformaldehyde (PFA) overnight, washed in PBS, cryoprotected in $30 \%$ sucrose, transferred in OCT compound, frozen, and sectioned at $12 \mu \mathrm{m}$. Newborns were perfused with $4 \%$ PFA, and either the brain was dissected, postfixed, washed in PBS, stained with 5-bromo4-chloro-3-indolyl- $\beta$-D-galactopyranoside (X-gal), and processed for cryostatic sections or the entire head was washed in PBS, stained with $\mathrm{X}$-gal, decalcified with $10 \%$ EDTA for $8 \mathrm{~h}$, and processed as above. $\beta$ gal + nuclei were detected by histoenzymatic staining with X-gal, as described previously (Merlo et al., 2002). Alternatively, $\beta$ gal + nuclei were detected by immunostaining with anti- $\beta$ gal antibody.

Immunohistochemistry was done on cryostatic sections, according to standard protocols. Permeabilization was done with $10 \%$ Triton X-100 at room temperature for $10 \mathrm{~min}$, followed by blocking with $10 \%$ goat serum and $0.5 \%$ Triton $\mathrm{X}-100$ for $1 \mathrm{~h}$ at room temperature. The following antibodies were used: rabbit anti- $\beta$ gal (1:5000; MP Biomedical, Illkirch, France), rabbit anti-S100 (1:200; DakoCytomation, Glostrup, Den- mark), goat anti-olfactory marker protein (OMP; 1:2000; Wako Chemicals, Neuss, Germany), rabbit anti-laminin (1:200) (Duband and Thiery, 1987), mouse anti-collagen type IV [monoclonal, 1:200; Developmental Studies Hybridoma Bank (DSHB), University of Iowa, Iowa City, IA], mouse anti-heparan sulfate (HSPG) and antichondroitin sulfate (CSPG) (monoclonal, 1:200; DSHB), mouse antivimentin (monoclonal, 1:500; DSHB), mouse anti-vinculin (monoclonal, 1:500; DSHB), anti-talin (1:100; Abcam, Cambridge, UK), mouse anti-neuronal class-III $\beta$-tubulin (monoclonal TuJ1, 1:1000; Sigma, St. Louis, MO), mouse anti-polysialic acid (PSA)-NCAM (monoclonal, 1:2000; AbCys, Paris, France), and goat anti-doublecortin (DCX; polyclonal, 1:500, C18; Santa Cruz Biotechnology, Santa Cruz, CA). Monoclonal antibodies were revealed with the ARK kit (DakoCytomation). Rabbit and goat antisera were revealed either with peroxidaseconjugated goat anti-rabbit (EnVision+; DakoCytomation) and rabbit anti-goat (Rockland, Gilbertsville, PA) antibodies, respectively, or with anti-mouse-Cy2 and anti-rabbit-Cy3 (1:200 and 1:600; Jackson ImmunoResearch, West Grove, PA) antibodies. Peroxidase was developed with DAB.

Bright-field micrographs were taken with a digital photocamera on an Olympus (Tokyo, Japan) AX70 microscope. Fluorescence micrographs were obtained with a confocal microscope (TCS SP2 AOBS; Leica, Nussloch, Germany), using the sequential scanning/stacking function with false colors, digitally merged. For colocalization, single Z-slices, rather than the Z-stack, were used.

Organotypic slice cultures. Donor and host tissues were obtained from E11.5 and E12.5 embryos, as indicated for each experiment. Embryonic heads were dissected in cold PBS-glucose $(0.6 \%)$, embedded in warm $\left(42^{\circ} \mathrm{C}\right) 3 \%$ low melting point agarose (Sigma), let harden at room temperature, and transferred on ice. The gel blocks were sectioned by a vibratome $(250 \mu \mathrm{m})$ and kept $1 \mathrm{~h}$ in PBS-glucose on ice. Slices were transferred on Millicell-CM membranes (Millipore, Billerica, MA) floating on DMEM/F-12 medium (Invitrogen, Carlsbad, CA), $6.5 \mathrm{mg} / \mathrm{ml}$ glucose, $0.1 \mathrm{~m}$ glutamine, and $10 \% \mathrm{FBS}$ at $37^{\circ} \mathrm{C}$ for $1 \mathrm{~h}$, changed to Neurobasal medium supplemented with B27 (Invitrogen), and maintained at $100 \%$ humidity, $5 \% \mathrm{CO}_{2}$ at $37^{\circ} \mathrm{C}$ for $48-72 \mathrm{~h}$.

The $\mathrm{OP}$ or the anterior $\mathrm{FB}$ tissues were removed from slices using a fine needle. For the grafting experiments, sections from $D l x 5-/-; \mathrm{BAT}^{\text {nlac } Z}$ mice were used as hosts, whereas $\beta$-actin-eGFP+ [wild-type (WT)] embryos were used as donors of normal OPs. The olfactory region of E11.5 embryos was dissected, vibratome sliced $(250 \mu \mathrm{m})$, and processed as described below. The donor heads were sectioned as for the host tissues, kept in cold PBS-glucose, and further dissected to separate OP fragments. These were transferred onto the host slices using a glass capillary; cultures were changed to Neurobasal/B27 and maintained for $48 \mathrm{~h}$. For the analyses, slices were fixed in 4\% PFA and examined by fluorescence microscopy, or stained with X-gal.

Blocking Wnt signal in slice cultures. Organotypic slice cultures were set up from E11.5 WT embryos, as described above. To visualize the olfactory nerves, we used embryos heterozygous for the tau-eGFP transgene. To test the efficacy of the Wnt inhibition, the same experiments were performed on slices of E11.5 BAT ${ }^{\text {nlac } Z}$ embryos. To antagonize the Wnt signal, we used heparin-acrylic beads (Sigma) adsorbed either with PBS alone (as negative controls) or with recombinant Dickkopf-1 (Dkk1; 25 $\mu \mathrm{g} / \mathrm{ml}$ in PBS $/ 0.1 \%$ BSA) or secreted Frizzled-related protein-2 (sFRP2; $10 \mu \mathrm{g} / \mathrm{ml}$ ) purified proteins ( $\mathrm{R} \& \mathrm{D}$ Systems, Minneapolis, MN). Beads were soaked in the protein solution for $8 \mathrm{~h}$ at room temperature and transferred onto the anterior forebrain surface (AFS) or onto the frontonasal process of the host slice.

Transfection and small interfering RNA. COS7 cells were transfected with plasmids expressing Wnt4-, Wnt5a-, and Wnt7b-mycTAG fusion proteins (obtained from Dr. Y. Zou, University of California, San Diego, La Jolla, CA) (Liu et al., 2005) using Lipofectamine-2000 (Invitrogen) and were tested for expression of Myc-tagged-Wnt fusion proteins by immunostaining with anti-mycTAG (monoclonal 9E10; Sigma). Transfected cells were replated $12 \mathrm{~h}$ after transfection, allowed to adhere to the surface, and used as feeder layer for organotypic cultures from E11.5 $\mathrm{BAT}^{\text {nlac } Z}$ embryos. Cultures were continued for $48 \mathrm{~h}$, fixed with $4 \% \mathrm{PFA}$ and stained with X-gal. 


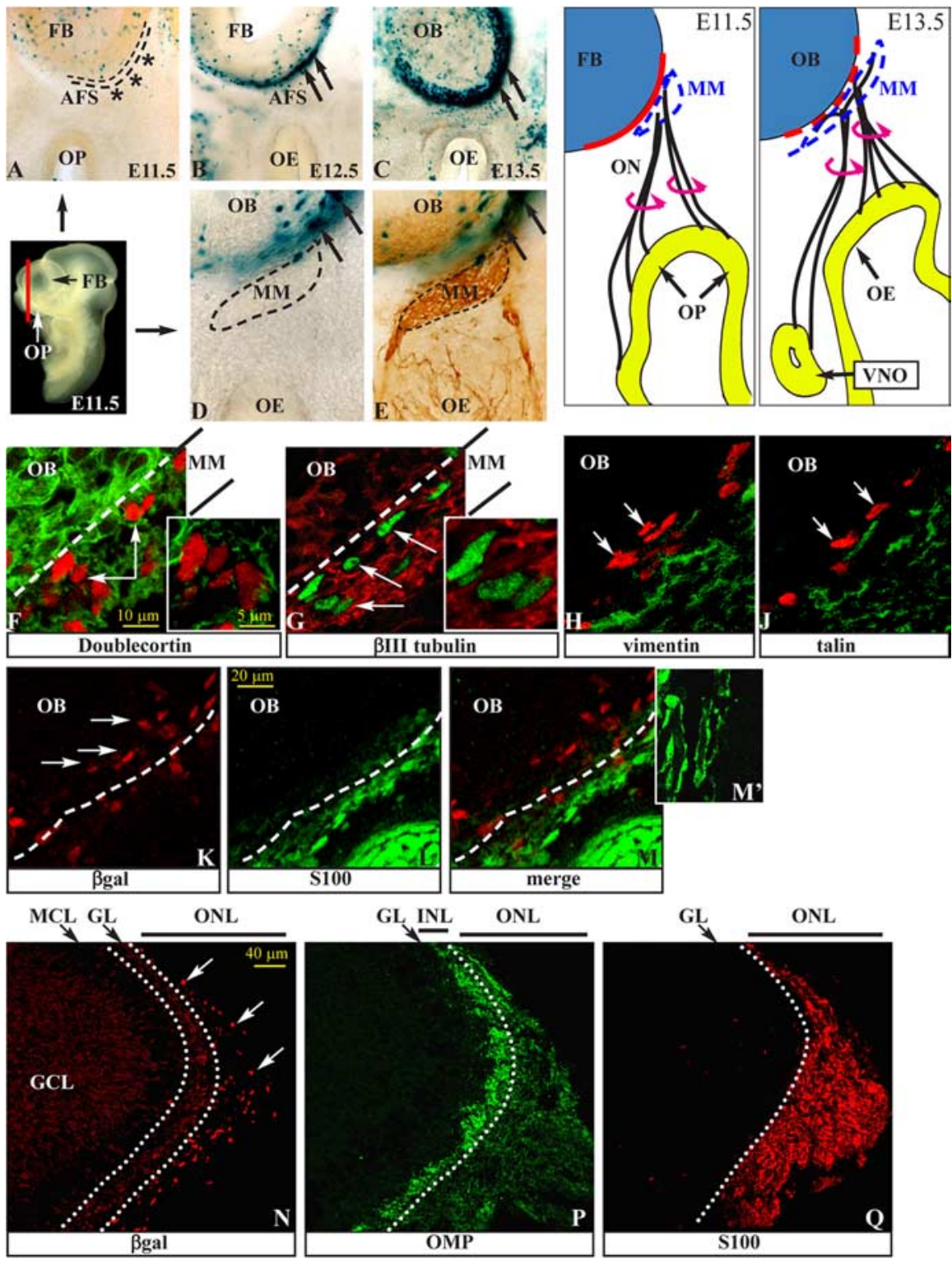

Figure 1. Wnt- $\beta$ catenin-responsive cells in the developing olfactory system. $\boldsymbol{A}-\boldsymbol{C}$, X-gal staining of frontal sections of $B A T^{n l a c z}$ embryos at E11.5 (A), E12.5 (B), and E13.5 (C). A section plane is shown (solid red line). $\beta$ gal + nuclei are visible around the $0 B$ at E12.5 and subsequent stages (black arrows) but not at E11.5 (black asterisks). D, E, X-gal staining of sections from E12.5 BAT ${ }^{\text {nlacZ }}$ embryos $(\boldsymbol{D})$, followed by immunostaining with anti-NCAM $(\boldsymbol{E})$, to show the position of the MM (area within the dashed line) and the $\beta \mathrm{gal}+$ nuclei. The drawings on the right show the relationship between ORN neurites and the FB at the same stages. $\boldsymbol{F}-\boldsymbol{J}$, Double immunostaining for $\beta$ gal (white arrows) and DCX ( $\boldsymbol{F}$, red), $\beta$ Ill-tubulin $(\boldsymbol{G}$, green), vimentin $(\boldsymbol{H}$, green), or talin $(\boldsymbol{J}$, green) on sections of E12.5 BAT ${ }^{\text {nlacZ }}$ embryos. Insets, Higher magnification of single confocal Z-slices. $\boldsymbol{K}-\boldsymbol{M}$, Double immunostaining for $\beta \mathrm{gal}\left(\boldsymbol{K}, \boldsymbol{M}\right.$, red) and $\mathbf{S 1 0 0}\left(\boldsymbol{L}, \boldsymbol{M}\right.$, green). $\boldsymbol{M}^{\prime}$, Higher magnification of $0 \mathrm{~N}$-associated $\mathbf{S 1 0 0}+$ cells. $\boldsymbol{N}-\boldsymbol{Q}$, Immunostaining for $\beta \mathrm{gal}$ $\left(\boldsymbol{N}\right.$, red, white arrows), $0 \mathrm{MP}\left(\boldsymbol{P}\right.$, green), and $\mathrm{S} 100\left(\boldsymbol{Q}\right.$, red) on consecutive sagittal sections of neonatal BAT ${ }^{\text {nlac } Z} ; D / \times 5^{+/ l a c Z} 0 \mathrm{~B}$. In $\boldsymbol{N}$, anti- $\beta$ gal also recognizes $0 B$ interneurons (weaker cytoplasmic signal). Dotted white lines separate the outer and the inner nerve sublayers. GCL, Granule cell layer; GL, glomerular layer; INL, inner nerve layer; $\mathrm{MCL}$, mitral cell layer; 0NL, outer nerve layer. transfected with a higher concentration $(300$ $\mathrm{nM}$ ) of siRNA, maintained for $48 \mathrm{~h}$, and stained with X-gal. Uptake of siRNA oligonucleotides was confirmed by fluorescence microscopy. Depletion of mRNA in the cultured OP was examined by real-time quantitative PCR (qPCR) after siRNA transfection.

Detection of Wnt and Frizzled mRNAs by reverse transcription-PCR, real-time $P C R$, and in situ hybridization. For reverse transcription (RT)-PCR and real-time PCR, OB, olfactory epithelium (OE), and AFS tissue fragments were dissected under microscopic examination from $100 \mu \mathrm{m}$ vibratome slices of E13.5 WT embryos and transferred in Trizol (Invitrogen), and total RNA was isolated according to the manufacturer's instructions and reverse transcribed ( $1 \mu \mathrm{g}$ of RNA) with SuperScript II RT (Invitrogen) at $42^{\circ} \mathrm{C}$ for $50 \mathrm{~min}$, with random hexamers. RT-PCR was performed using standard cycle programs and reagents. Real-time qPCR was performed with LightCycler and FastStart DNA MasterPLUS SYBR-Green I (Roche, Milan, Italy). Each sample was done in triplicate, and experiments were repeated twice. Standard curves were determined using WT cDNA with four calibration points: 1:1; 1:3; 1:9; 1:27. Specificity and absence of primer dimers was controlled by denaturation curves on the PCR products. GAPDH (glyceraldehyde-3phosphate dehydrogenase) mRNA was used for normalization, calculated using LightCycler software 3.5.3. Intron-spanning oligonucleotides were designed to amplify the cDNA of all the Wnt and the following Frizzled ( $F z d$ ) genes: Fzd1, Fzd3, Fzd4, Fzd5, Fzd7, and Fzd9.

In situ hybridization was performed with digoxigenin-labeled RNA probes obtained by in vitro transcription. Wnt2 and Wnt11 were gifts from Dr. A. McMahon (Harvard University, Boston, MA), Wnt $5 a$ and $W n t 5 b$ were gifts from Dr. Y. Yang (National Human Genome Research Institute, Bethesda, MD), Fzd4 and Fzd5 were gifts from Dr. S. Pleasure (University of California San Francisco, San Francisco, CA), and $F z d 9$ was from Dr. L. Muzio (DiBit-San Raffaele, Milan, Italy). Other probes were obtained by RT-PCR cloning and were sequence verified, and the signal obtained was consistent with available data (www.genepaint.org). Hybridization was done on cryostatic sections from E12.5-E14.5 embryos, using published procedures (Merlo et al., 2002), and revealed with BM Purple (Roche). After hybridization, selected sections (from BAT ${ }^{\text {nlacZ }}$ specimens) were rinsed in PBS and immunostained for Bgal.

Alexaflour488- and Cy3-labeled Wnt7b and control small interfering RNAs (siRNAs) were synthesized (Qiagen, Hilden, Germany) with the following sequence: Wnt7b (1), forward 5'GCAUGAAGCUGGAAUGUAdTdT, reverse 5' UUACAUCCAGCUUCAUGCdGdG; Wnt7b (2), forward 5' CCUGGAUCAUGCACAGAAAdTdT, reverse 5' UUUCUGUGCAUGAUCCAGGdGdA; control, forward 5' UUUUCCGAACGUGUCACGUdTdT, reverse 5' ACGUGACACGUUCGGAGAAdTdT.

Their efficiency was examined in COS7 cells transfected with $0.8 \mu \mathrm{g}$ of Wnt7b-mycTAG expression plasmids, followed by retransfection with $50 \mathrm{~nm}$ siRNA (and control), using Hyperfect reagent (Qiagen) according to instructions. Cells were then immunostained for mycTAG $24 \mathrm{~h}$ later and scored. Organotypic cultures from E11.5 BAT ${ }^{\text {nlacz }}$ embryos were

\section{Results}

\section{Wnt- $\boldsymbol{\beta}$ catenin-responsive cells and early} ORN-FB innervation

To investigate the distribution of Wnt-responsive cells in the olfactory pathway, we examined mice carrying the BAT ${ }^{\text {nlacz }}$ reporter. In these mice, cells responding to a Wnt signal through the $\beta$ catenin pathway express $\beta$ gal in their nuclei and can be visualized (Maretto et al., 2003). We stained sections of BAT ${ }^{\text {nlac } Z}$ heterozygous embryos of several ages. At E12.5, $\beta$ gal + nuclei were present on the ventromedial surface of the anterior $\mathrm{FB}$, the 

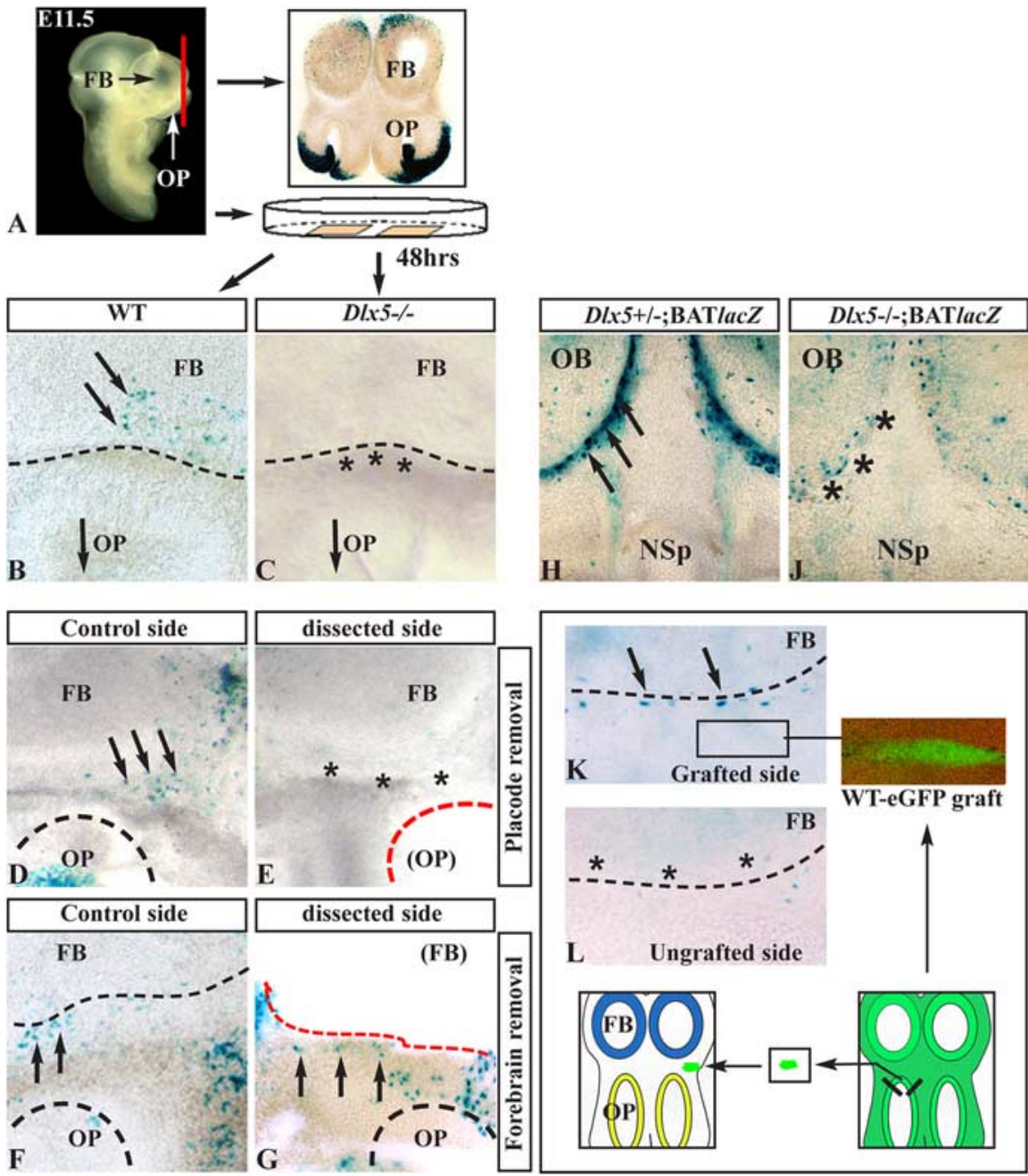

Figure 2. Organotypic cultures to define the origin of Wnt signal. $A$, Section plane and experimental procedure using organotypic cultures. $B, C$, Sections of E11.5 BAT ${ }^{\text {nlacz }}$ WT $(\boldsymbol{B})$ and BAT ${ }^{\text {nlacZ }} ; D 1 \times 5-1-(C)$ embryos, cultured for $48 \mathrm{~h}$ and stained with X-gal. $\beta \mathrm{gal}+$ nuclei (black arrows) are visible in the WT but not in the DIX5-/ - (black asterisks). $\boldsymbol{D}, \boldsymbol{E}$, Removal of one OP (dashed red line) from slices of E11.5 BAT ${ }^{\text {nlacz }}$ WT embryos: $\beta \mathrm{gal}+$ nuclei are detected in the control sections (black arrows) but absent after $O P$ removal (black asterisks). $\boldsymbol{F}, \boldsymbol{G}$, Same as in $\boldsymbol{D}$ and $\boldsymbol{E}$ but removing the $F B$ (dashed red line). The number of $\beta$ gal + nuclei is not greatly reduced compared with the control side. $\boldsymbol{H}, \boldsymbol{J}$, Coronal sections of E13.5 embryos with genotypes $B A T^{\text {nlacz }} ; D 1 \times 5+/-(\boldsymbol{H})$ and BAT ${ }^{\text {nlac }} ; D 1 \times 5-/-(J)$, stained with X-gal. The DlX5 - / - sections show a drastic reduction in $\beta$ gal + nuclei (black asterisks) compared with the Dlx 5 heterozygous ones (black arrows). $K, L$, Grafting of fragments of OP from E11.5 eGFP + WT donor embryos onto slices from $\mathrm{E} 11.5 \mathrm{BAT}^{\mathrm{nlac}} ; \mathrm{D} / \times 5-1-$ embryos. The donor tissue was placed anterior to the $\mathrm{FB}$, as illustrated in the drawing (bottom) and indicated in $\boldsymbol{K}$. After culture, $\beta$ gal + nuclei were detected (X-gal staining) in the AFS of grafted slices (arrows in $\boldsymbol{K}$ ) but not in the control side (asterisks in $\boldsymbol{L}$ ). NSp, Nasal septum.

region that is the precursor to the $\mathrm{OB}$. This region is referred to as the AFS (Fig. $1 A-E$, black arrows). The number of $\beta$ gal + nuclei increased at E13.5 and persisted at all subsequent embryonic ages (Fig. $1 A-E$ ) and in the neonatal OB (Fig. $1 N$ ). $\beta g$ gal + nuclei were absent from the AFS at and before E11.5 (Fig. 1A). With the exception of a few positive nuclei associated with developing blood vessels (late embryonic/postnatal) or displaced by the vibratome sectioning, there was no expression in the OP (early embryo), the $\mathrm{OE}$ (late embryonic/postnatal), the $\mathrm{MM}$, and the olfactory and vomeronasal nerves. Intense $\mathrm{X}$-gal staining was observed in the mesenchyme of the frontonasal processes (Fig. 2A), as expected.

At E12-E13, ORN axons and OP-derived migratory cells form a cap-like structure, called the $\mathrm{MM}$, against the ventromedial end of the anterior FB. The MM contains axons and migratory cells positive for NCAM (Fig. 1E). The $\beta$ gal+ nuclei located at the ventromedial edge of the anterior $\mathrm{FB}$ were internal with respect to the MM cap and did not express NCAM, suggesting they are not neuronal (Fig. 1D,E). We can also exclude the cells as Cajal-Retzius cell bodies because of the absence of NCAM and $\beta$ III-tubulin, normally expressed by this cell type.

The MM contains a population of migrating cells derived from the OP, among which are $\mathrm{GnRH}+, \mathrm{NCAM}+$, and DCX neurons (Wray et al., 1989; Tarozzo et al., 1995). The $\beta$ gal + nuclei at the surface of the FB could belong to these migratory cells. However, at E12.5, $\beta$ gal + nuclei are already present on the surface of the FB, whereas migratory cells are found only along the emerging axon bundles and in the MM; thus, the migratory origin of these cells appears unlikely. However, we performed double immunostaining of sections from E12.5 embryos to detect $\beta$ gal and either DCX, a marker for migratory and immature neurons, or $\beta$ III-tubulin, a general marker for the neuronal lineage (Menezes and Luskin, 1994; Gleeson et al., 1999). At E12.5, $\beta \mathrm{gal}+$ nuclei were located at the boundary between the MM and the FB and were surrounded by DCX + and $\beta$ III-tubulin + cell bodies and neurites, but they did not show immunoreactivity for either of these markers in their cytoplasms (Fig. 1F,G). DCX+ cell bodies were abundant in the OB; however, none of their nuclei was $\beta g a l+$. Staining for PSA-NCAM yielded the same result (data not shown). These data point to both a non-neuronal and nonmigratory nature of the $\beta$ catenin-activated cells. Finally, in Dlx5-/- embryos, OP-derived cell migration is essentially eliminated as a consequence of the primary lack of ORN axon innervation (see below). After grafting a WT OP onto slices from Dlx5-/-;BATnlacZ embryos, $\beta$ catenin response can be restored, providing another indication that the $\beta$ catenin-activated cells are not derived from OP migration.

Mesenchymal-type cells are present in and around the olfactory pathway, and some are tightly associated with the BM of the FB. Vimentin, vinculin, and talin are known markers for mesenchymal cells (Hay, 1989; Treloar et al., 1996). We performed double immunohistochemistry on sections from E12.5 BAT $^{\text {nlac } Z}$ embryos to determine whether $\beta$ gal + cells express any of these mesencymal markers. Expression of all these markers was abundant and widespread in the head mesenchyme, but only low expression of talin, vimentin, and vinculin (data not shown) was observed in the MM and at the interface between the $\mathrm{MM}$ and the $\mathrm{FB}$, where $\beta g a l+$ nuclei are located (Fig. $1 H-J$ ). No $\beta$ gal + nuclei coexpressed these mesenchymal markers. However, the Wnt receptor gene $\mathrm{Fzd7}$ is expressed at the site where $\beta$ gal+ nuclei are located (Fig. $3 E$ ), and $\beta$ gal + nuclei are closely associated with the BM (supple- 

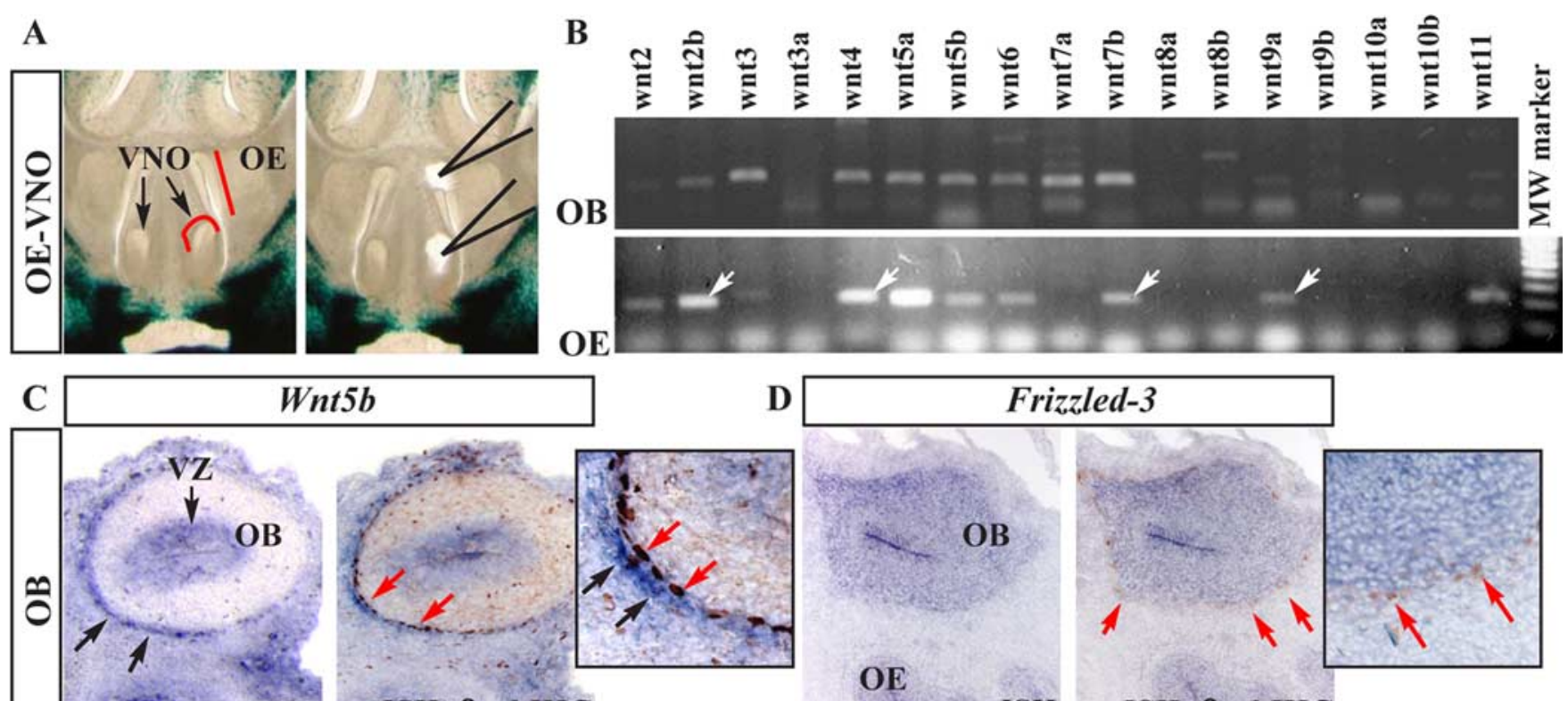

Frizzled-3

ISH $18 \mathrm{H}+\beta \mathrm{gal}$ IHC
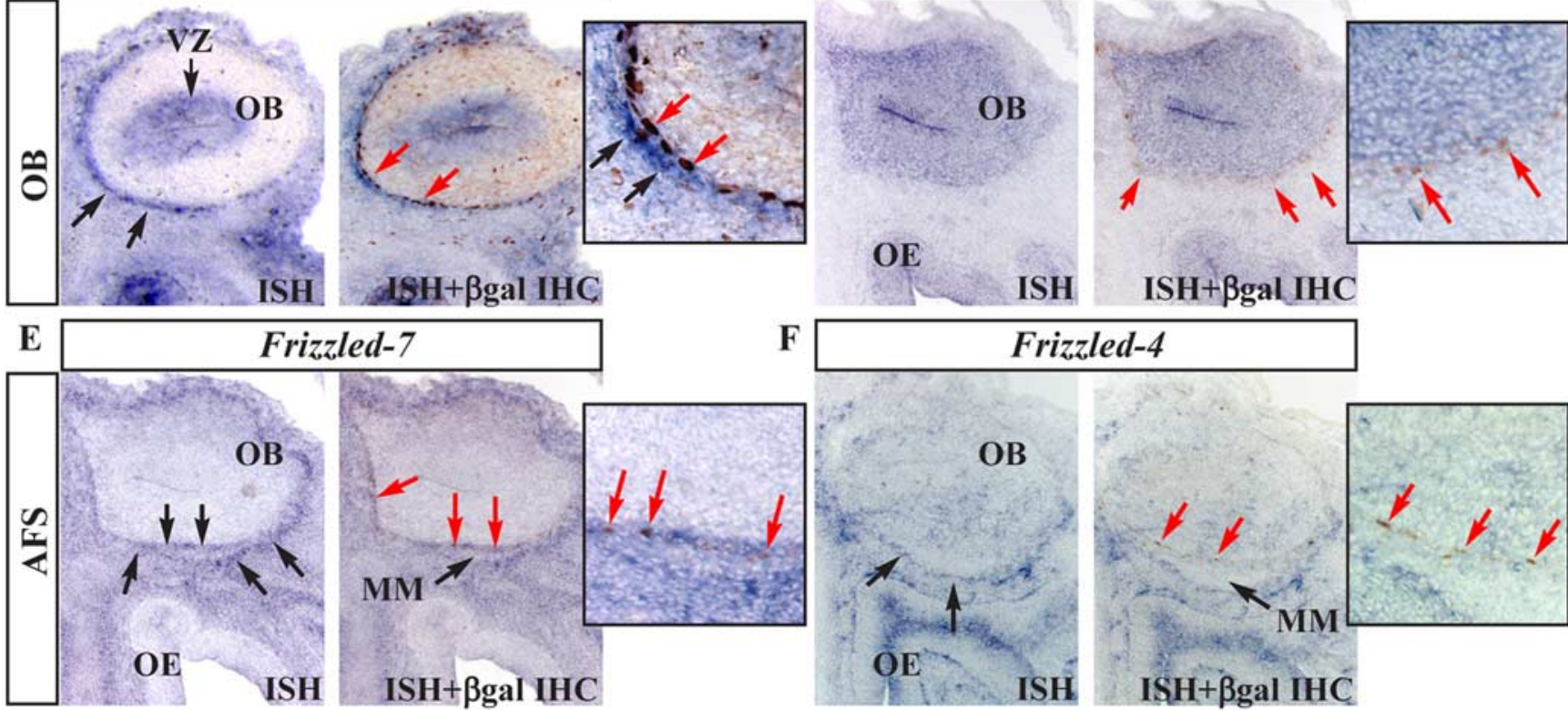

OE

ISH ISH+Bgal IHC
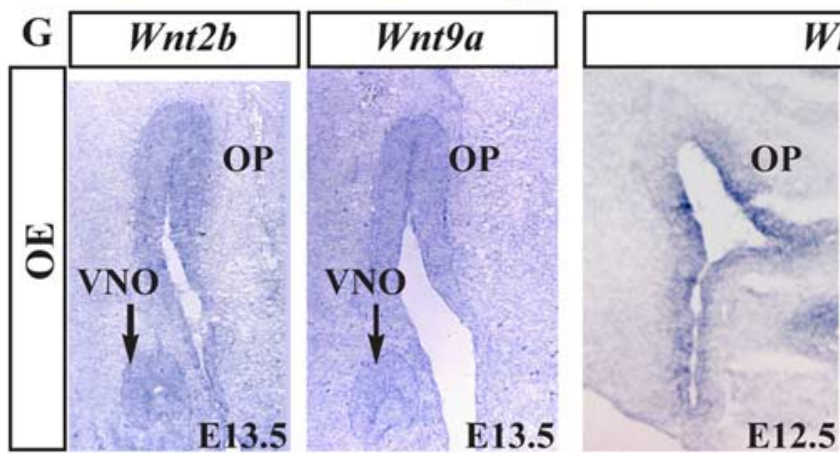

Wnt7b
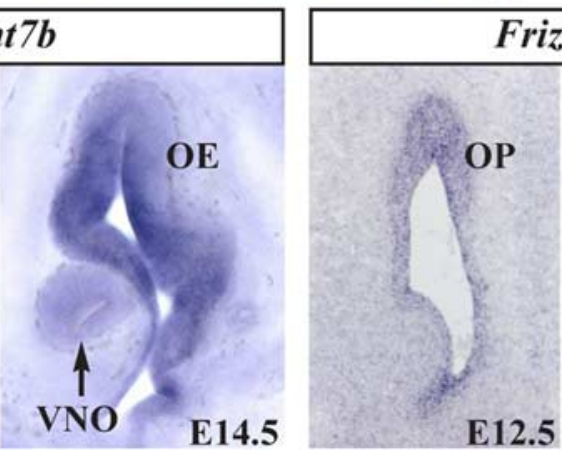

MM

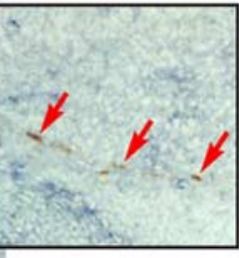

Figure 3. Expression of Wnt and Fzd genes in the embryonic olfactory system. A, Dissection of 0 E and VNO tissues from slices of E13.5 embryos. OB was obtained from more rostral slices. $\boldsymbol{B}$, RT-PCR amplification for Wnt mRNAs (as indicated on top) on dissected OB (top) or OE plus VNO (bottom) from E13.5 WT embryos. "Canonical" Wnt genes expressed in the OE-VNO are indicated (white arrows). MW, Molecular weight. $\boldsymbol{C}-\boldsymbol{F}$, In situ hybridization (ISH) with probes for Wnt5b (C), Fzd3 (D), Fzd7 (E), and Fzd4 (F) on frontal sections of E14.5 embryos (left, blue, black arrows), followed immunostaining for $\beta$ gal (right, brown nuclei, red arrows). Insets show higher magnifications. $\beta$ gal + nuclei are found in the Fzd7 expression domain of the AFS. VZ, Ventricular zone. G, Expression of selected Wnt and Fzd genes in the embryonic $\mathrm{OE}$ and VNO. Embyonic stages are indicated at the bottom.

mental Fig. 1, available at www.jneurosci.org as supplemental material). Thus, $\beta$ gal + cells, if mesodermal in origin, are clearly nontypical mesenchymal cells.

The MM also contains migratory cells that are the precursors of olfactory ensheathing cells (OECs), a population of Schwann-like cells that expresses S100. We therefore examined whether the $\beta$ gal + nuclei could belong to early OEC-like cells. Using double immunohistochemistry, we determined that $\beta g a l+$ nuclei are located in a layer internal with respect to that of the $\mathrm{S} 100+$ cell bodies in the MM (Fig. $\left.1 K-M^{\prime}\right)$ and did not express S100. By birth, the (OMP+) layers of the OB have reorganized into a glomerular layer and two nerve sublayers: an outer layer, rich in laminin/collagen-IV and containing abundant S100+ cells, and an inner one, low in laminin/ collagen-IV and devoid of S100+ cells (Bailey et al., 1999). Because of the position of $\beta$ gal + nuclei external to the embryonic FB, we predicted that at birth these nuclei should be absent from the glomerular and inner nerve sublayer and instead be located in the outer sublayer. We immunostained sections of $\mathrm{BAT}^{\text {nlacZ }} ; D l \times 5+/-$ OB for $\beta$ gal, OMP, and S100. The Dlx5-lacZ allele provided a marker for OB interneurons (Levi et al., 2003) that can be distinguished for the weak cyto- 
Table 1. Wnt- $\beta$ catenin response in cultured slices from $B A T^{\text {nlacz }}$ embryos: removal of $O P$ and $F B$ from WT slices

\begin{tabular}{|c|c|c|}
\hline & OP removal ${ }^{a}$ & FB removal $^{a}$ \\
\hline Total & $40^{b}$ & 30 \\
\hline Presence of X-gal + nuclei & $7(18 \%)$ & $28(93.3 \%)$ \\
\hline Absence of X-gal + nuclei $^{d}$ & $33(82 \%)$ & $2(6.7 \%)$ \\
\hline
\end{tabular}

${ }^{a}$ Slices from E11.5 embry0s, maintained in culture for $48 \mathrm{~h}$.

${ }^{b}$ Numbers of slices showing the indicated response.

X-gal-stained nuclei (nuclear $\beta$ gal + ) detected in AFS.

${ }^{d}$ Same as in footnote $c$; absence of $X$-gal-stained nuclei.

plasmic staining. $\beta$ gal + nuclei were located within the $\mathrm{OMP}+; \mathrm{S} 100+$ layer but were absent from the $\mathrm{OMP}+; \mathrm{S} 100-$ layer (Fig. 1N-Q).

With the exception of a few pioneer axons entering the anterior FB before E10.5 (Key, 1998; Astic et al., 2002), at E12.5 the MM and the FB are separated by a BM, which in late embryonic stages is extensively degraded and fenestrated to allow for the formation of the nerve layer (Doucette, 1989). This BM is composed of laminin, collagen-IV, and proteoglycans of the CSPG and the HSPG classes (Gong and Shipley, 1996; Treloar et al., 1996; Julliard and Hartmann, 1998). The position of $\beta$ gal + nuclei with respect to the BM was assessed by double immunostaining for $\beta$ gal and either collagen-IV or HSPG, on E12.5 and E14.5 $\mathrm{BAT}^{\text {nlacZ }}$ embryonic heads. $\beta$ gal + nuclei were often found associated with the internal surface of the BM, and their position often corresponded to areas where the BM appears discontinuous and fenestrated (supplemental Fig. 1, available at www.jneurosci.org as supplemental material). Staining with CSPG antibody yielded results identical to HSPG (data not shown). At subsequent stages, the association of the $\beta g a l+$ nuclei with the fenestrations of the $\mathrm{BM}$ is maintained.

ORN to mesenchymal signals induce Wnt- $\beta$ catenin response Neurite-to-mesenchyme signaling is thought to be essential for initial ORN axons pathfinding and connectivity (Calof and Chikaraishi, 1989; LaMantia et al., 2000). The Wnt- $\beta$ catenin response on the surface of the FB could be elicited by signals from the OP, from the mesenchyme, or even from the FB. To investigate the source of Wnt signaling to these cells, we developed culture conditions that preserve the $\mathrm{OP}-$ mesenchyme-FB organization and maintain Wnt- $\beta$ catenin cell activation. We prepared organotypic slice cultures of the olfactory region, using BAT $^{\text {nlac } Z}$ embryos (Fig. 2A). Because $\beta$ gal + nuclei associated with the anterior FB are present at E12.5 but not at earlier stages (Fig. 1), we expect that if slices are cut at E11.5 and recapitulate in vivo development, $\beta$ gal + nuclei should appear within $24-48 \mathrm{~h}$ in vitro. Indeed, after $48 \mathrm{~h}, \beta \mathrm{gal}+$ nuclei were detected at the edge of the $\mathrm{FB}$, a region corresponding to the AFS (Fig. $2 A, B$ ).

Using this culture system on BAT ${ }^{\text {nlacZ }}$ embryo slices, we then removed either the OP or the FB from one side of the sections, retaining the contralateral side for control. Removal of the OP resulted in a near complete loss of $\beta$ gal + nuclei from the AFS in the majority of slices (33 of 40), whereas removal of the FB tissue

Table 2. Wnt- $\beta$ catenin response in cultured slices from $B A T^{\text {nlacz }}$ embryos: comparison between WT and D/x5-/- slices

\begin{tabular}{llc}
\hline & WT $^{a}$ & ${\text { DlX5 }-1-{ }^{a}}^{a}$ \\
\hline Total & 30 & 10 \\
Presence of X-gal+ nuclei $^{b}$ & 28 & 0 \\
\hline
\end{tabular}

${ }^{a}$ Slices from E11.5 embry0s, maintained in culture for $48 \mathrm{~h}$.

${ }^{b} \mathrm{X}$-gal-stained nuclei (nuclear $\beta \mathrm{gal}+$ ) detected in AFS.
Table 3. Wnt- $\beta$ catenin response in cultured slices from $B A T^{\text {nlacz }}$ embryos: rescuing the $\beta$ catenin response in D/x $5-/-$ embryos

\begin{tabular}{ll}
\hline Total & 8 \\
Presence of X-gal + nuclei $^{a}$ & 7 \\
\hline
\end{tabular}

${ }^{a} X$-gal-stained nuclei (nuclear $\beta$ gal + ) detected in AFS.

rarely resulted in loss of $\beta$ gal + nuclei ( 2 of 30 ) (Fig. $2 D-G$; Table $1)$. These data suggest that an OP-derived signal(s) is required to activate the $\beta$ catenin pathway in the AFS. Because the OP is at some distance from the responsive cells, this signal molecule(s) is most likely released from extended ORN axons as they approach the $\mathrm{FB}$ region. Of note, neither the OP nor the mesenchyme around the olfactory pathway display $\mathrm{Wnt}-\beta$ catenin-responsive cells, another indication that the activating signal is conveyed by the axons and targeted to the AFS region.

To complement this observation, and to verify that removal of the OP does not change local expression of Wnt and Fzd in the AFS, we determined the mRNA abundance of $W n t 5 b$ and three $F z d$ genes ( $F z d 3, F z d 4$, and $F z d 7$ ) in the AFS (see below) of cultured slices, in which the OP was either removed or left in place. We did not observe any reduction, but rather a modest increase, in the expression of these genes (supplemental Fig. $2 \mathrm{~A}$, available at www.jneurosci.org as supplemental material).

\section{Reduced Wnt- $\beta$ catenin activation in Dlx5-/- embryos}

We also examined the role of olfactory axons approaching the FB for the activation of the $\beta$ catenin pathway, by using a genetic model for lack of axon-FB contact, that would not require drastic manipulation such as OP removal. In the absence of Dlx5, ORN neurites elongate and extend toward the FB but inevitably fail to make contact and form connections, as the consequence of cellautonomous defects in ORN axons (Levi et al., 2003; Long et al., 2003; Merlo et al., 2007). If neurite-to-mesenchyme signals near the FB are critical to activate the Wnt- $\beta$ catenin pathway, the disrupted axon growth in Dlx5-1- embryos should result in an absence of $\beta$ gal + nuclei. Indeed, in $D l \times 5-/-;$ BAT $^{\text {nlac } Z}$ embryos, the number of $\beta g a l+$ nuclei is drastically reduced $(-75$ to $-85 \%$ ) compared with WT or Dlx5+/ - controls (Fig. $2 H, J$ ). As expected, organotypic slice cultures established from E11.5

Table 4. Expression of Wnt and Fzd genes in the embryonic olfactory system

\begin{tabular}{|c|c|c|c|c|c|}
\hline & RT-PCR & In situh & tion & RT-PCR & In situ \\
\hline & WT OB & WT OB & WT AFS & WT OE & WT OE-VNO \\
\hline$W n t 2^{a}$ & $+1-$ & - & - & + & $+1-$ \\
\hline Wnt2b & + & - & + & + & + \\
\hline Wnt3 & ++ & $+^{b}$ & - & $+1-$ & $+1-^{b}$ \\
\hline Wnt4 & ++ & ++ & $+1-$ & + & + \\
\hline Wnt5a & ++ & $++^{c}$ & - & + & - \\
\hline Wnt5b & ++ & $++^{c}$ & ++ & + & + \\
\hline Wnt6 & + & $++^{b}$ & - & + & + \\
\hline Wnt7a & +++ & nd & nd & - & nd \\
\hline Wnt7b & +++ & $+^{c}$ & - & + & + \\
\hline Wnt9a & + & $++^{b}$ & - & + & + \\
\hline Wnt11 & $+1-$ & - & $++^{b}$ & + & $+1-^{b}$ \\
\hline$F z d 1^{a}$ & & $++^{c}$ & - & & - \\
\hline$F z d 3$ & & $+^{b}$ & - & & + \\
\hline Fzd4 & & $+1-$ & $+1-$ & & $+1-$ \\
\hline Fzd7 & & - & ++ & & - \\
\hline$F z d 9$ & & $+^{c}$ & - & & - \\
\hline
\end{tabular}

+++ , High; ++ , present; + , low; - , absent; nd, not done.

${ }^{a}$ Additional $W n t$ and $F z d$ genes examined but not included in this list because expression was undetectable: Wnt1 Wnt3a, Wnt8a, Wnt8b, Wnt9b, Wnt10a, Wnt10b, and Fzd5.

${ }^{b}$ Widespread expression.

Ventricular zone of the embryonic $\mathrm{OB}$. 


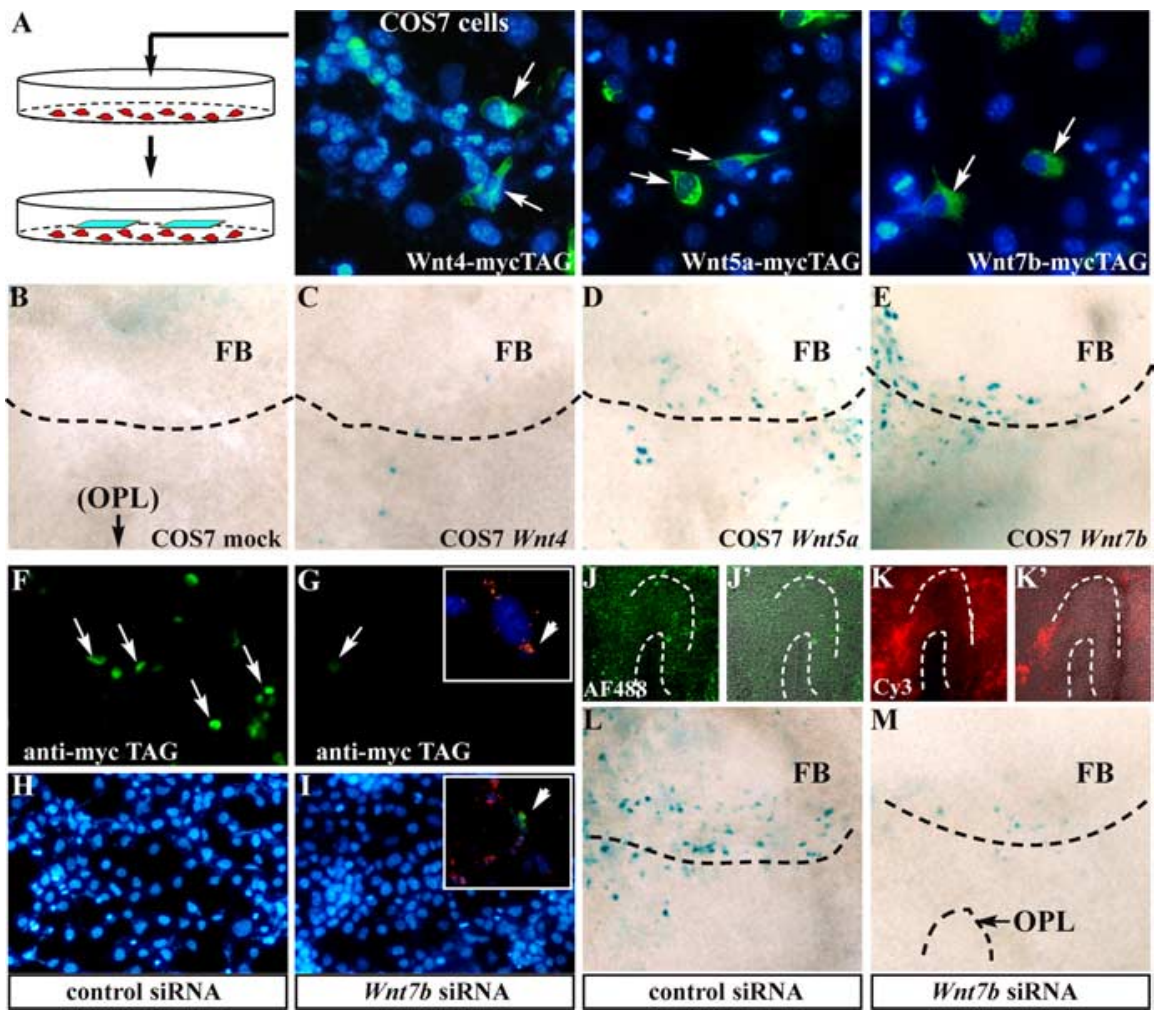

Figure 4. Wnt7b and Wnt5a are sufficient to activate $\beta$ catenin response on the surface of the FB. $A$, Detection of Wnt-mycTAG proteins in COS7 transfected with the indicated expression plasmids. mycTAG + cells are indicated (white arrows). 4',6Diamidino-2-phenylindole (DAPI) was used for counterstaining. $\boldsymbol{B}-\boldsymbol{E}$, Effect of Wnt4-, Wnt5a-, and Wnt7b-expressing feeder layers $(\boldsymbol{C}-\boldsymbol{E})$ on transfected $\mathrm{E} 11.5 \mathrm{BAT}^{\text {nlacZ }}$ embryos, from which the OP has been removed, compared with slices maintained with mock-transfected cells $(\boldsymbol{B})$. X-gal + nuclei are rescued in the presence of Wnt5a and Wnt7b but not Wnt4. F-I, Depletion of Wnt-mycTAG protein in transfected COS7 cells after treatment with the control $(\boldsymbol{F}, \boldsymbol{H})$ and the Wnt7b siRNA $(\boldsymbol{G}, \boldsymbol{I})$. mycTAG + cells are indicated (white arrows). Insets, Uptake of the fluorescent siRNA duplex and DAPI counterstaining. $\boldsymbol{J}-\boldsymbol{K}^{\prime}$, Detection of the Alexafluor488-labeled (control; $\boldsymbol{J}, \boldsymbol{J}^{\prime}$ ) and $\left(y 3\right.$-labeled $\left(W n t 7 b ; \boldsymbol{K}, \boldsymbol{K}^{\prime}\right)$ siRNA duplex in transfected slices. $\boldsymbol{J}^{\prime}$ and $\boldsymbol{K}^{\prime}$ are overlays of bright-field and fluorescence images. $\boldsymbol{L}, \boldsymbol{M}$, Effect of control $(\boldsymbol{L})$ and $W n t 7 b(\boldsymbol{M})$ siRNA on slices from E11.5 BAT ${ }^{\text {nlacz }}$ embryos. The number of X-gal + nuclei is significantly reduced. OPL, olfactory placode.

Dlx5-/-;BAT ${ }^{\text {nlac } Z}$ embryos also failed to show $\beta$ gal + nuclei in the AFS (Fig. 2C, Table 2).

The absence of $\beta g a l+$ nuclei in the AFS of Dlx5-1- embryos could be attributable to either the absence of the responsive cells or a failure of activation of present cells. If the second case was true, grafting a normal OP in a $D l \times 5-/-$ slice should restore Wnt- $\beta$ catenin response. However, if the cells are absent, "rescue" with WT OP would be ineffective. We combined the technique of organotypic cultures of $\mathrm{BAT}^{\text {nlac } Z}$ Dlx5-/- embryos with the grafting of a normal OP obtained from $\beta$-actin-eGFP+ embryos of the same age. The donor tissue fragment was positioned near the AFS, on one side of the section, with the contralateral side left intact as a control. Grafting a WT OP near to the AFS resulted in restoration of $\beta$ gal expression at the boundary of the anterior FB (seven of eight slices) (Fig. $2 K, L$; Table 3 ). This indicates that an OP signal induces $\mathrm{Wnt}-\beta$ catenin response, a function that is absent in $D l \times 5-/-$ mice caused only by the absence of Dlx5-1- axons reaching the FB.

To better characterize the Dlx5 mutant model, we examined expression of some of the relevant Wnt and Fzd genes (see below) in the OP and mesenchyme by in situ hybridization and real-time qPCR, comparing WT and Dlx5-1- samples. Wnt $2 b, W n t 7 b$, and $\mathrm{Fzd} 3$ (OP expressed) were expressed at an equal level. Wnt5b expression (in the mesenchyme around the OB) was reduced, whereas $F z d 7$ expression (mesenchyme) was not significantly changed (supplemental Fig. 2A-H, available at www.jneurosci.org as supplemental material, and data not shown). Finally, grafting experiments indicate that the olfactory connectivity defect in Dlx 5 null animals is linked to cell-autonomous properties of ORNs and does not depend on the OB (Levi et al., 2003; Merlo et al., 2007).

\section{Expression of Wnt and Fzd genes in the} olfactory system

Obvious candidates for OP-derived signals inducing Wnt- $\beta$ catenin response are the Wnt genes themselves. First, we screened for expression of all Wnts by RTPCR on RNA from dissected the OE and vomeronasal organ (VNO) from E13.5 WT embryos (Fig. 3A). As control for the efficiency of the RT-PCRs, a mix of total RNA from embryos at various stages was used with each primer pair generating an appropriate positive control amplicon (data not shown). We detected expression of Wnt2, Wnt2b, Wnt3, Wnt4, Wnt5a, Wnt5b, Wnt6, Wnt7b, Wnt9a, and Wnt11 (Fig. 3B; Table 4). However, the dissected OE will inevitably contain some of the associated mesenchyme. To better localize the expression of Wnt genes, we performed in situ hybridization on sections of E12.5-E14.5 WT heads. Wnt2b, Wnt7b, and $W n t 9 a$ are expressed in the OE-VNO (Fig. 3G, Table 4; supplemental Fig. 2, available at www.jneurosci.org as supplemental material), Wnt5a is expressed in the submucosal mesenchyme and not the $\mathrm{OE}$, and Wnt4 is detected in the non-OE of the nasal cavity (data not shown).

Then, we screened for expression of Wnt genes on RNA from dissected WT OB at E13.5. By RT-PCR, we detected expression of Wnt2b, Wnt3, Wnt4, Wnt5a, Wnt5b, Wnt6, Wnt7a, Wnt7b, $W n t 9 a$, and $W n t 11$ (Fig. 3B; Table 4). By in situ hybridization, we found that $W n t 4, W n t 5 a, W n t 5 b$, and $W n t 7 b$ are expressed in the ventricular zone of the $\mathrm{OB}$, whereas $W n t 2 b$ and $W n t 9 a$ are expressed throughout the $\mathrm{OB}$ (supplemental Fig. 2, available at www.jneurosci.org as supplemental material, and data not shown). Wnt5b is expressed in the mesenchyme surrounding the OB (AFS), near the $\beta$ gal + nuclei (Fig. $3 C$; supplemental Fig. 2, available at www.jneurosci.org as supplemental material).

We examined expression of $F z d$ genes in the olfactory system of E12.5-E14.5 WT embryos (Fig. 3D-G; Table 4). Fzd3 is expressed throughout the OE-VNO and OB; Fzd4, Fzd7, and Fzd9 are expressed in the mesenchyme surrounding the $\mathrm{OB}$, near the $\beta$ gal + nuclei. We decided to determine the position of the $\beta$ gal + nuclei relative to the expression of Wnt and Fzd genes. We hybridized sections from E14.5 BAT ${ }^{\text {nlac } Z}$ embryos for Wnt4, Wnt5b, Wnt7b, Fzd1, Fzd3, Fzd4, Fzd7, and Fzd9 and immunostained the sections with anti- $\beta$ gal. Stained nuclei were found within the $F z d 7$ expression domain around the OB (Fig. 3E), adjacent (but internally) with respect to the $W n t 5 b$ domain (Fig. $3 C$ ) but distant from the $F z d 1, F z d 4$, and $F z d 9$ (mesenchymal) domains (Fig. $3 F)$. Furthermore, $\beta$ gal + nuclei were found externally to the Fzd3 (OB) domain (Fig. 3D), as expected. No other Fzd gene 
expression colocalized with the position of the $\beta$ gal + nuclei. Thus, the $\beta$ cateninactivated cells on the surface of the OB most likely respond to the Wnt signal(s) via Fzd7. A modest increase in Fzd7 expression is observed after OP removal (supplemental Fig. $2 \mathrm{~A}$, available at www.jneurosci.org as supplemental material), possibly reflecting the absence of the activating signal.

\section{Wnt7b and Wnt5a are sufficient to activate $\boldsymbol{\beta}$ catenin response.}

Of the OP-expressed Wnt genes, Wnt $2 b$, $W n t 4, W n t 7 b$, and $W n t 9 a$ are known activators of the canonical pathway. Expression of $W n t 5 b$, in the mesenchyme around the FB, could also play a role. $W n t 5 b$ displays the highest sequence identity (>95\%) with Wnt5a, known to activate the $\beta$ catenin pathway when interacting specifically with Fzd7 (Zou, 2004). Wnt4, expressed only in the respiratory epithelium, is unlikely to activate Fzd receptors in the AFS. We transfected Wnt4-,
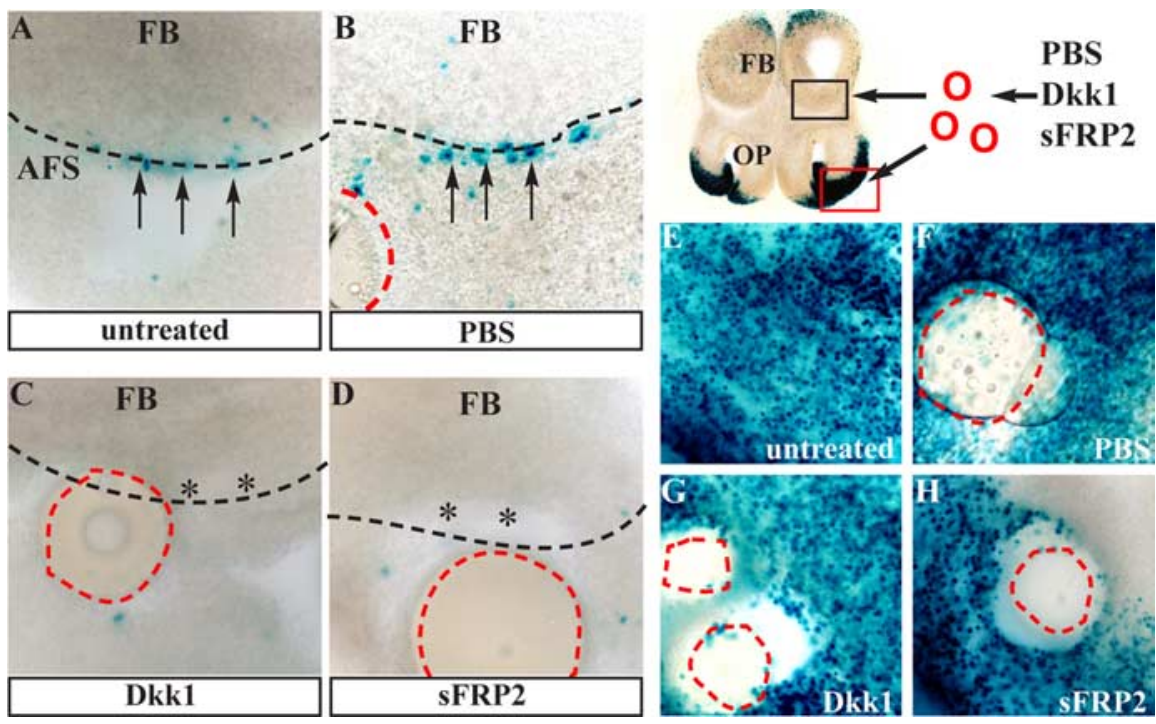

Figure 5. $\boldsymbol{A}-\boldsymbol{D}$, Blocking canonical Wnt signal in the AFS of E11.5 BAT ${ }^{\text {nlacz }}$ embryos, with beads incubated with Dkk1 $(\boldsymbol{C})$ or sFRP2 (D); as control, the untreated side $(\boldsymbol{A})$ or PBS-soaked bead $(\boldsymbol{B})$ are shown. $\boldsymbol{E}-\boldsymbol{H}$, Same as before $(\boldsymbol{A}-\boldsymbol{D})$, except that beads were placed onto the frontonasal processes. The number of $X$-gal + nuclei is reduced near the bead $(\boldsymbol{G}, \boldsymbol{H})$. The control side (untreated or PBS) is shown $(\boldsymbol{E}, \boldsymbol{F})$. Black arrows and asterisks indicate, respectively, presence and absence of $X$-gal-stained nuclei. The position of the bead is shown with dashed red lines. Wnt5a-, and Wnt7b-mycTAG expression plasmids into COS7 cells (Liu et al., 2005) and used these cells as the feeder layer for slice cultures of E11.5 BAT ${ }^{\text {nlaZ }}$ embryos (Fig. $4 A)$. The OP was removed from one side of each slice, leaving the counterlateral OP for control. Wnt7b- and Wnt5a-expressing COS7 cells restored $\beta$ gal + nuclei in, respectively, 8 of 10 and 12 of 14 slices, whereas the control Wnt4-expressing or mocktransfected COS7 cells did not (Fig. 4B-E). On intact slices, we did not observe any significant increase in X-gal+ cells, suggesting that all potentially responsive cells are normally activated by the OP (data not shown). These data show that Wnt7b or Wnt5a alone are sufficient to activate the $\beta$ catenin pathway in the olfactory-associated, Wnt-responsive cells. However, a potential role for Wnt2b or other Wnts expressed by the OP or the mesenchyme around the OB cannot be excluded.

\section{Wnt7b is partly required to activate $\beta$ catenin response}

At early stages of development, $W n t 7 b$ is expressed in the OP and in the FB (Fig. 3G; Suppl. Fig. 2C). We hypothesized that if exogenous Wnt7b can activate $\beta$ gal cells in $\mathrm{BAT}^{\text {nlac } Z}$ organotypic slices in the absence of an OP, then inhibition of the Wnt7b signal should abolish $\beta$ gal expression when an OP is present. To inhibit Wnt7b, we used an siRNA approach to reduce endogenous Wnt7b production. First, we tested $W n t 7 b$ and control siRNA on COS7 cells transfected with a Wnt7b-mycTAG expression plasmid: a $>85 \%$ reduction in the number of mycTAG + cells was observed after transfection of $W n t 7 b$ siRNA compared with control siRNA (Fig. $4 F-I$ ). Next, we transfected slices of E11.5 BAT $^{\text {nlac } Z}$ embryos and maintained them in culture for $48 \mathrm{~h}$. $W n t 7 b$ siRNA resulted in a clear reduction in the number of $\mathrm{X}$-gal + cells in the AFS ( -60 to $-80 \%$; five of six slices), whereas the control siRNA had no effect (eight of eight) (Fig. $4 L, M$ ). siRNA duplexes were tagged with Alexafluor488 and Cy3, and we could verify the uptake of the siRNA duplexes both in COS7 cells and in cultured slices by fluorescence microscopy (Fig. $4 \mathrm{~J}, \mathrm{~K}^{\prime}$ and insets). Real-time qPCR on RNA extracted from pools of dissected OP showed a modest $15-20 \%$ reduction in the Wnt7b mRNA in samples treated with $W n t 7 b$ siRNA compared with
Table 5. Effect of Wnt/Fzd inhibition on olfactory connection: inhibition of $\beta$ catenin activation

\begin{tabular}{lll}
\hline & Dkk1 & sFRP2 \\
\hline Total & 7 & 9 \\
Reduced X-gal $^{a}$ & 1 & 1 \\
Absence of X-gal $^{b}$ & $6(86 \%)$ & $8(89 \%)$ \\
\hline
\end{tabular}

${ }^{a}$ Number of slices in which X-gal + nuclei were significantly reduced in number (at least $-70 \%$ ), after the application of the Wnt inhibitor.

${ }^{b}$ Number of slices in which X-gal + nuclei were absent.

control siRNA (data not shown). However, even this modest reduction in mRNA resulted in a pronounced reduction in the activation the $\beta$ catenin cells in the AFS. Together, these results show that $W n t 7 b$ is a major component of the activation of the $\beta$ catenin pathway on the surface of the OB. The presence of residual X-gal+ cells after treatment with $W n t 7 b$ siRNA is an indication of the role of other Wnts expressed by the OE and by the mesenchyme surrounding the OB.

\section{Canonical Wnt signals are required to activate $\boldsymbol{\beta}$ catenin response}

If canonical Wnt signals are essential for the observed activation of the $\beta$ catenin response in the AFS, then antagonists to this pathway should also abolish this response. We used recombinant Dkk1 and sFRP2 as antagonists. These two naturally occurring polypeptides are expressed during embryonic development and can inhibit the canonical Wnt-Fzd pathway extracellularly. Dkk1 blocks the interaction of Fzd receptors with LDL (low-density lipoprotein) receptor-related protein (Kawano and Kypta, 2003), whereas sFRPs resemble membrane-bound Fzd and competitively bind to Wnts to reduce the level of ligand available to interact with the receptors. Importantly, both Dkk1 and sFRP2 are known or proposed to specifically interfere with signaling by Wnt7a and Wnt7b (Kim et al., 2001; Caricasole et al., 2003; Kawano and Kypta, 2003), which are $>95 \%$ identical. We therefore assayed the efficacy of these inhibitors on slice cultures of BAT $^{\text {nlacZ }}$ embryos by placing beads soaked with Dkk1 or sFRP2, 
either on the AFS (Fig. $5 A-D$ ) or on the frontonasal processes (Fig. $5 E-H$ ). Dkk1 and sFRP2 were able to drastically reduce the number of X-gal+ nuclei in the AFS (Fig. 4C,D; Table 5). In the frontonasal processes, in which the Wnt- $\beta$ catenin response is very abundant, $\mathrm{X}$-gal + nuclei were reduced only in the proximity of the beads (Fig. 4G,H). Control slices untreated or treated with PBS-soaked beads showed no alteration in X-gal staining. Thus, both inhibitors are effective in blocking the Wnt canonical signal in cultured slices.

\section{Wnt/Fzd antagonists Dkk and sFRP inhibit olfactory connectivity}

To examine the role of Wnt- $\beta$ catenin signaling at the surface of the FB in ORN axons connectivity, the trajectory of ORN axons was visualized using transgenic embryos expressing the fluorescent marker eGFP under control of the tau promoter (Tucker et al., 2001). We readily detected eGFP fluorescence in early olfactory axons in slice cultures (Fig. 6A, $A^{\prime}$ ). Beads soaked in Wnt/Fzd inhibitors were placed near the AFS of E11.5 tau-eGFP slices and maintained for $24 \mathrm{~h}$ in culture.

When Dkk1 or sFRP was used, frequently the axon bundles failed to reach the $\mathrm{FB}$, and most processes remained near the OP or adopted an abnormal trajectory (Dkk1 maximum concentration, 14 of 16; sFRP2 maximum concentration, 19 of 19) (Fig. 6C-H; Table 6). In contrast, when PBS or highly diluted (1:20) Dkk1 or sFRP2 was used, alterations of axon trajectory were rarely observed; axon bundles coursed around the beads to reach the FB (PBS, 28 of 34; Dkk1, 8 of 9; sFRP2, 14 of 16).

Misguided axons may fail to contact the FB as a consequence of altered trajectory or have intrinsic problems of connectivity independent of the trajectory. To begin to distinguish "guidance" versus "connectivity" defects, we soaked the beads with an intermediate concentration of Dkk1 or sFRP2 (1:5 and 1:10, respectively): this condition rarely elicited drastic changes on axon trajectory, whereas the effect on connectivity was prominent (Fig. $6 E, F$; Table7). Thus, blocking of the Wnt- $\beta$ catenin response in the AFS can affect connectivity with the FB even when axons adopt a "normal" trajectory.

\section{Discussion}

Morphogenesis and wiring of the embryonic olfactory system requires interactions between cells and signals of different origin, including the OP, migratory cells, nasal mesenchyme, and FB (Bailey et al., 1999; Lin and Ngai, 1999; St. John et al., 2002; Bashin et al., 2003; Brunjes and Greer, 2003; Nedelec et al., 2005). Here we describe a novel Wnt-responsive cell population, closely associated with the surface of the FB at the location of the initial ORN axon-to-FB contact. Activation of the $\beta$ catenin pathway in these cells is associated with expression of the $F z d 7$ receptor gene in the same region but critically depends on initiating signals from the OP, among which Wnt7b is sufficient to perform this function. Blocking Wnt/Fzd activation in the region of axon con- tact results in a severely reduced number of ORN axons reaching the FB. These data suggest that neurite-induced Wnt- $\beta$ catenin activation is needed for the establishment of the early olfactory pathway, a novel function for this pleiotropic family of morphogens. We propose that the OP-derived Wnt signal is released and/or active during axon-FB contact and can recruit responsive cells of mesodermal origin to participate in tissue remodeling of the primitive BM that, in turn, is essential for the formation of the nerve layer of the OB.

The appearance of the olfactory Wnt-responsive cells corresponds with early ORN axon-to-FB contact (E11-E12). The location of these cells at the interface of the FB and mesenchyme suggest several potential origins, such as migratory cells from the OP or mesenchymal cells of the BM. We have characterized these cells and have established (1) the absence of typical markers for migratory neurons (DCX and PSA-NCAM), (2) the absence of the OEC marker S100, and (3) the absence of mesenchymal markers vimentin, vinculin, and talin. $\beta$ catenin response can be restored in Dlx5-/- embryos, in which OP-derived cell migration is necessarily interrupted (Levi et al., 2003; Merlo et al., 2007), excluding a placodal migration origin of these cells. Importantly, the receptor $F z d 7$ is expressed in the same mesenchymal location as the $\beta$ catenin-activated cells but is excluded from the MM. Together, the data suggest that the Wnt- $\beta$ cateninresponsive cells are a population of nontypical resident mesoderm-derived cells, distinct from more typical ones.

Wnt molecules have been implicated as key morphogens in several developmental processes (Logan and Nusse, 2004). We assessed the function of "canonical" Wnt signaling in the olfactory region 
Table 6. Effect of Wnt/Fzd inhibition on olfactory connection: effect on ORN axons, at maximal concentration

\begin{tabular}{|c|c|c|c|}
\hline & PBS & Dkk1 & SFRP2 \\
\hline Total $^{a}$ & 34 & 16 & 19 \\
\hline Normal trajectory and connection ${ }^{b}$ & $28(82 \%)$ & $2(12 \%)$ & $0(0 \%)$ \\
\hline Lack of connection only & $6(18 \%)$ & $11(68 \%)$ & $15(79 \%)$ \\
\hline Lack of connection and altered trajectory ${ }^{d}$ & 0 & 3 & 4 \\
\hline
\end{tabular}

${ }^{a}$ Number of slices in which ORN axons could be visualized.

${ }^{b}$ Number of slices in which ORN axons were normally oriented and contacted the FB.

'Number of slices in which ORN axons were normally oriented but failed to contact the FB.

${ }^{d}$ Number of slices in which ORN axons show abnormal trajectory and (consequently) lack of connection.

Table 7. Effect of Wnt/Fzd inhibition on olfactory connection: effect on ORN axons, at reduced concentration

\begin{tabular}{|c|c|c|c|c|}
\hline & \multicolumn{2}{|l|}{ Dkk1 } & \multicolumn{2}{|l|}{ sFRP2 } \\
\hline & $1: 5$ & $1: 20$ & $1: 10$ & $1: 20$ \\
\hline Total $^{a}$ & 6 & 9 & 7 & 16 \\
\hline Normal trajectory and connection ${ }^{b}$ & $1(17 \%)$ & $8(88 \%)$ & $1(14 \%)$ & $14(87 \%)$ \\
\hline Lack of connection only ${ }^{c}$ & $4(67 \%)$ & $1(11 \%)$ & $5(71 \%)$ & $2(12 \%)$ \\
\hline Lack of connection and altered trajectory ${ }^{d}$ & 1 & 0 & 1 & 0 \\
\hline
\end{tabular}

${ }^{a}$ Number of slices in which ORN axons could be visualized.

${ }^{b}$ Number of slices in which ORN axons were normally oriented and contacted the FB.

cNumber of slices in which ORN axons were normally oriented but failed to contact the FB.

${ }^{d}$ Number of slices in which ORN axons show abnormal trajectory and (consequently) lack of connection.

using assays based on cultures of BAT ${ }^{\text {nlac } Z}$ slices, in which axon growth and Wnt signaling is preserved. The BAT ${ }^{\text {nlac } Z}$ model used in this study visualizes only the canonical Wnt response (Maretto et al., 2003), which involves stabilization and nuclear translocation of $\beta$ catenin (Wang and Wynshaw-Boris, 2004; Widelitz, 2005). In general, members of the Wnt1 subclass (including Wnt1, Wnt2, Wnt3, Wnt7, and Wnt8) are potent activators of this pathway, whereas members of the Wnt5a subclass (including Wnt4, Wnt5, Wnt8, and Wnt11) are poor activators or, in some cases, inhibitors (Torres et al., 1996; Yamaguchi, 2001; Church et al., 2002; Oishi et al., 2003; Topol et al., 2003; Maye et al., 2004; Tian et al., 2005). However, signaling pathway specificity exerted by distinct Wnt molecules is highly dependent on the Fzd receptor repertoire, their coreceptors, and subcellular localization, rather than Wnt ligand (Wu et al., 2004; Mikels and Nusse, 2006). Of the first subclass, only Wnt2b, Wnt7b, and $W n t 9 a$ are expressed in the OP: here we show that exogenous Wnt7b is sufficient, and partly necessary, to rescue the $\beta$ catenin signaling after OP removal. Therefore, we hypothesize that Wnt7b is the main physiological $\beta$ catenin activator, although the contribution of other Wnts of either placodal or mesencymal origin cannot be excluded.

We also found that exogenous expression of Wnt5a is able to restore $\beta$ catenin activation on the surface of the FB. This Wnt does not usually activate the $\beta$ catenin pathway, whereas it is known to promote $\beta$ catenin degradation (Topol et al., 2003). Wnt5b (the closest homolog to $W n t 5 a$ ) is expressed in the AFS, the location where ORN axons/MM contact the FB, adjacent to the $\beta$ gal+ nuclei. $W n t 5 b$ is endogenously expressed around the $\mathrm{OB}$ and might also contribute to the activation of $\beta$ catenin in the AFS, possibly secondary to the arrival of the ORN in proximity of the OB. Our observation on the activity of exogenously added Wnt5a is in accord with the fact that the $F z d 7$ gene, the only Fzd receptor expressed in the AFS, is known to mediate both $\beta$ catenin-dependent (Linker et al., 2005; Abu-Elmaqd et al., 2006) and $\beta$ catenin-independent (DeCalisto et al., 2005) signaling. Furthermore, Wnt5a can specifically activate the $\beta$ catenin signal in the presence of the Fzd7 (Zou, 2004) or the Fzd4 (Mikels and Nusse, 2006) receptors. We have detected expression of $F z d 7$, but not $F z d 4$, in the Wnt- $\beta$ catenin-responsive cell location, therefore the Wnt5b-Fzd7 pathway can potentially contribute to $\beta$ catenin activation on the FB surface. Thus, at least two Wnt molecules can activate the $\beta$ catenin pathway on the FB surface, suggesting some degree of redundancy. Conversely, depletion of Wnt7b reduces $\beta$ catenin activation in the responsive cells, thus Wnt7b is likely to be the primary signal. Finally, the role of "noncanonical" Wnt genes expressed by the OP cells is unclear. As shown for Wnt5a (Topol et al., 2003), noncanonical Wnt can modulate the $\beta$ cateninactivating function of the canonical ones, or alternatively perform as yet unknown functions.

Our data indicate that the initial signal for the activation of Wnt$\beta$ catenin response is derived from the OP. In fact, grafting of a WT OP onto slices from Dlx5-/- embryos restores the $\beta$ catenin response in this region. Thus, we must postulate that the ORN axonderived signal(s) is initially required for activating the $\beta$ catenin response in cells adjacent to the surface of the FB. Together with the observation that Wnt- $\beta$ catenin signaling is required for ORN axons to target the FB, these data show a novel function of specific Wht genes. This class of morphogens is required for (centripetal-type) connectivity of olfactory axons with the CNS.

Blocking Wnt/Fzd activation with exogenous Dkk1 and sFRP2 results in reduced growth, abnormal orientation, and lack of axon-FB connectivity. In this experimental setup, however, both connectivity and axon guidance seem to be affected. It is important to note that axon-guidance functions for Wnt molecules have been demonstrated recently: in vivo Wnt4/Fzd3 signaling guide dorsal commissural axons in the embryonic spinal chord, and in vitro Wnt1, Wnt4, Wnt5a, Wnt6, and Wnt7b polypeptides can stimulate axon extension (Lyuksyutova et al., 2003; Liu et al., 2005). Interestingly, the anterior FB expresses the Wnt4 gene, and the embryonic OP expresses the $F z d 3$ receptor. Therefore, Wnt signaling might logically contribute to elongation and guidance of newly sprouted ORN neuritis during development of the olfactory system, expanding the guidance functions of Wnt molecules to the peripheral neurites (Zou, 2004; Bovolenta, 2005; Ille and Sommer 2005). This interesting possibility will have to be investigated with appropriate models and tools.

OB innervation is thought to be coordinated by local interactions between the ORN axons, migratory cells, and the BM that surrounds the FB, whereas the FB itself does not seem to play a major role (Levi 

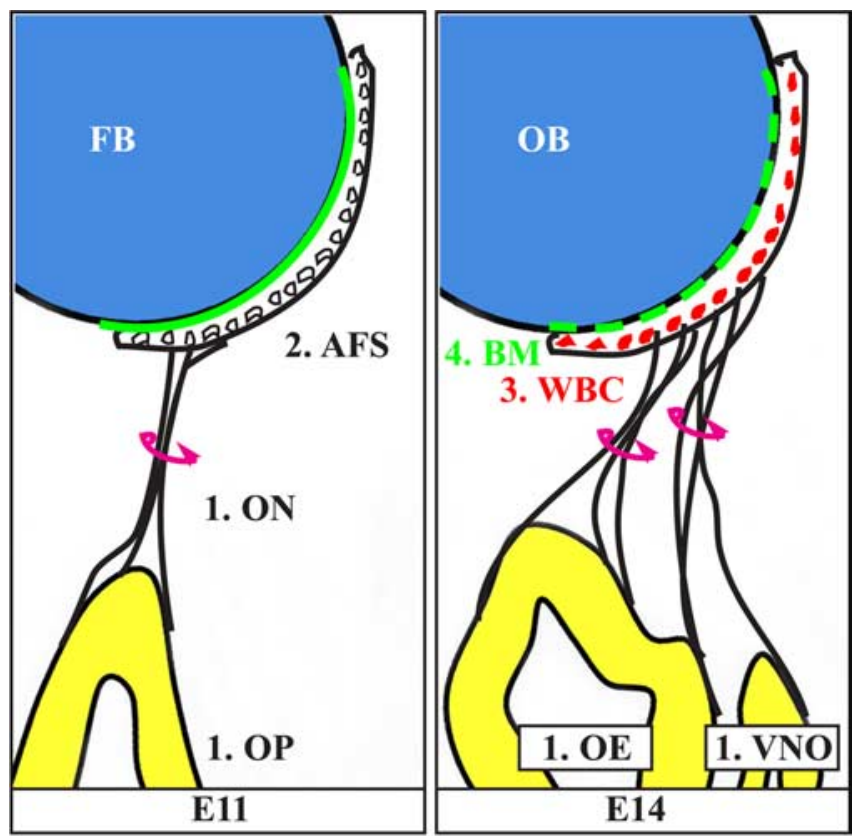

\section{Wnt7b \\ Wnt2b Wnt9a \\ 2. Fzd7 Wnt5b \\ 3. $\beta$-catenin \\ 4. MMPs activation \\ Fenestration}

Figure 7. Model of Wnt signaling in olfactory connectivity. The stages depicted are E11E14. The AFS is indicated with a white crescent, and the Wnt- $\beta$ catenin cells (WBC) are depicted in red, near the surface of the FB (blue). The BM is shown with a solid (E11) or a dashed (E14) green line on the surface of the FB. Initial axon sprouting and elongation is controlled cellautonomously by transcription factors (such as Emx2, D/x5, and Fez1) and locally by early patterning cues. ORN cells express canonical Wnt genes; among these, Wnt7b is sufficient for the subsequent functions (step 1). Axons elongate and contact the FB within the AFS region (step 2); this contact is required for delivery and/or release of $\beta$ catenin-activating Wnt molecules. Cells resident on the surface of the $O B$ express $F z d 7$ and activate the $\beta$ catenin pathway in response to Wnts (step 3). We hypothesize that these cells are involved in the subsequent remodeling and fenestration of the BM (step 4).

et al., 2003; Hirata et al., 2006). The molecular events leading to BM fenestration and formation of the nerve layer are primarily unknown. ORN axons arrive near the BM of the anterior FB and organize in the $\mathrm{MM}$, much before the neurites are able to contact the $\mathrm{FB}$, with the exception of the pioneer fibers, the function for connectivity of which remains elusive. Abundant innervation of the presumptive $\mathrm{OB}$ is visible around E13-E14, when the BM separating the MM from the FB parenchyma fenestrates extensively and allows the MM to wrap onto the surface of the OB (Doucette, 1989). The position of Wnt-responsive cells, at the interface of the BM and FB at early stages, suggests that these cells may play a role in cell-cell and cellextracellular matrix (ECM) interactions that coordinate ECM degradation and remodeling necessary for the formation of the nerve layers and synaptic contact. In Dlx5-1- embryos, the BM remains unfenestrated (our unpublished results), and the Wnt- $\beta$ catenin response in the same region is strongly reduced, despite the fact that the mutant ORN axons do come to a close proximity with the FB (Merlo et al., 2007). Interestingly, fibronectin has been reported to be a direct target of Wnt/Wg signaling in Xenopus fibroblasts (Gradl et al., 1999), and $\beta$ catenin is known to be associated with cell adhesion complexes and to regulate cell-substrate adhesion (Gottardi and Gumbriner, 2004). One possibility is that Wnt signaling on the surface of the OB activates the ECM remodeling functions of resident mesenchymal cells.

Our data suggest a model (Fig. 7) in which early olfactory axons extend through the nasal mesenchyme and approach the FB conveying OP-derived Wnt molecules to the mesenchyme surrounding the $\mathrm{OB}$. This activates a Wnt-dependent $\beta$ catenin response pathway in $F z d 7$-expressing resident cells, before the formation of the nerve layer. Among the OP-expressed Wnt molecules, Wnt7b is sufficient and partly necessary for the activation of the pathway, but Wnt2b and Wnt9a may complement Wnt7b function. The OP is also likely to convey signals that activate or induce the release of mesenchymal $W n t 5 b$, able to activate $\beta$ catenin on the surface of the FB through $F z d 7$. Subsequently, $\beta$ catenin-activated cells are possibly linked to the fenestration of the $\mathrm{BM}$ and $\mathrm{OB}$ innervation. This newly revealed role of Wnt molecules in olfactory connectivity contributes to clarify how distinct cell types interact on the surface of the anterior FB to coordinate this complex developmental process.

\section{References}

Abu-Elmaqd M, Garcia-Morales C, Wheeler GN (2006) Frizzled7 mediates canonical Wnt signaling in neural crest induction. Dev Biol 298:285-298 Acampora D, Merlo GR, Paleari L, Zerega B, Mantero S, Barbieri O, Postiglione MP, Simeone A, Levi G (1999) Craniofacial, vestibular and bone defects in mice lacking the distal-less-related gene Dlx5. Development 126:3795-3809.

Astic L, Pellier-Monnin V, Saucier D, Charrier C, Mehlen P (2002) Expression of netrin-1 and netrin-1 receptor, DCC, in the rat olfactory nerve pathway during development and axonal regeneration. Neuroscience 109:643-656.

Au WW, Treloar HB, Greer CA (2002) Sublaminar organization of the mouse olfactory bulb nerve layer. J Comp Neurol 446:68-80.

Bailey MS, Puche AC, Shipley MT (1999) Development of the olfactory bulb: evidence for glia-neuron interactions in the glomerular formation. J Comp Neurol 415:423-448.

Bashin N, Maynard TM, Gallagher PA, LaMantia AS (2003) Mesenchymalepithelial regulation of retinoic acid signaling in the olfactory placode. Dev Biol 261:82-98.

Binder LI, Frankfurter A, Rebhun LI (1985) The distribution of tau in the mammalian central nervous system. J Cell Biol 101:1371-1378.

Bovolenta P (2005) Morphogen signaling at the vertebrate growth cone: a few case or a general strategy? J Neurobiol 64:405-416.

Bozza T, Feinstein P, Zheng C, Mombaerts P (2002) Odorant receptor expression defines functional units in the mouse olfactory system. J Neurosci 22:3033-3043.

Brunjes PC, Greer CA (2003) Progress and directions in olfactory development. Neuron 38:371-374

Calof AL, Chikaraischi DM (1989) Analysis of neurogenesis in a mammalian neuroepithelium: proliferation and differentiation of an olfactory neuron precursor in vitro. Neuron 3:115-127.

Caricasole A, Ferraro T, Iacovelli T, Barletta E, Caruso A, Melchiorri D, Terstappen G, Nicoletti F (2003) Functional characterization of Wnt7a signaling in PC12 cells: interaction with a FZD5 $\times$ LRP6 receptor complex and modulation by Dickkopf proteins. J Biol Chem 278:37024-37031.

Church V, Tsutomu N, Linker C, Marcell C, Francis-West P (2002) Wnt regulation of chondrocyte differentiation. J Cell Sci 115:4809-4818.

DeCalisto J, Araya C, Marchant L, Riaz CF, Mayor R (2005) Essential role of non-canonical Wnt signaling in neural crest migration. Development 132:2587-2597.

Dode C, Hardelin JP (2004) Kallmann syndrome: fibroblast growth factor signaling insufficiency? J Mol Med 82:725-734.

Doucette R (1989) Development of the nerve fiber layer in the olfactory bulb of mouse embryos. J Comp Neurol 285:514-527.

Duband JL, Thiery JP (1987) Distribution of laminin and collagens during avian neural crest development. Development 101:461-478.

Fueshko S, Wray S (1994) LHRH cells migrate on peripherin fibers I embryonic olfactory explant cultures: an in vitro model for neurophilic neuronal migration. Dev Biol 166:331-348.

Gao PP, Sun CH, Zhou XF, DiCicco-Bloom E, Zhou R (2000) Ephrins stimulate or inhibit neurite outgrowth and survival as a function of neuronal cell type. J Neurosci Res 60:427-436.

Gleeson JG, Lin PT, Flanagan LA, Walsh CA (1999) Doublecortin is a microtubule-associated protein and is expressed widely by migrating neurons. Neuron 23:257-271. 
Gong Q, Shipley MT (1996) Expression of extracellular matrix molecules and cell surface molecules in the olfactory nerve pathway during early development. J Comp Neurol 366:1-14.

Gonzàlez-Martinez D, Hu Y, Bouloux PM (2004) Ontogeny of GnRH and olfactory neuronal systems in man: novel insights from the investigation of inherited forms of Kallmann's syndrome. Front Neuroendocrinol 25:108-130.

Gottardi CJ, Gumbiner BM (2004) Distinct molecular forms of betacatenin are targeted to adhesive or transcriptional complexes. J Cell Biol 167:339-349.

Gradl D, Kuhl M, Wedlich D (1999) The Wnt/Wg signal transducer betacatenin controls fibronectin expression. Mol Cell Biol 19:5576-5587.

Hay ED (1989) Extracellular matrix, cell skeletons, and embryonic development. Am J Med Genet 34:14-29.

Hirata T, Nazakawa M, Yoshihara S, Miyachi H, Kitamusa K, Yoshihara Y, Hibi M (2006) Zinc-finger gene Fez in the olfactory sensory neurons regulates development of the olfactory bulb non-cell-autonomously. Development 133:1433-1443.

Ille F, Sommer L (2005) Wnt signaling: multiple functions in neural development. Cell Mol Life Sci 62:1100-1108.

Julliard AK, Hartmann DJ (1998) Spatiotemporal patterns of expression of extracellular matrix molecules in the developing and adult rat olfactory system. Neuroscience 84:1135-1150.

Kawano Y, Kypta R (2003) Secreted antagonists of the Wnt signalling pathway. J Cell Sci 116:2627-2634.

Key B (1998) Molecular development of the olfactory nerve pathway. Ann NY Acad Sci 855:76-82.

Kim AS, Anderson SA, Rubenstein JL, Lowenstein DH, Pleasure SJ (2001) Pax-6 regulates expression of SFRP-2 and WNT-7b in the developing CNS. J Neurosci 21:RC312.

LaMantia AS, Bashin N, Rhodes K, Heemskerk J (2000) Mesenchymalepithelial induction mediates olfactory pathway formation. Neuron 28:411-425.

Levi G, Puche AC, Mantero S, Barbieri O, Trombino S, Paleari L, Egeo A, Merlo GR (2003) The Dlx 5 homeodomain gene is essential for olfactory development and connectivity in the mouse. Mol Cell Neurosci 22:530-543.

Li HS, Chen JH, Wu W, Fagaly T, Zhou L, Yuan W, Dupuis S, Jiang ZH, Nash W, Gick C, Ornitz DM, Wu JY, Rao Y (1999) Vertebrate slit, a secreted ligand for the transmembrane protein roundabout, is a repellent for olfactory bulb axons. Cell 9:807-818.

Lin DM, Ngai J (1999) Development of the vertebrate main olfactory system. Curr Opin Neurobiol 9:4-8.

Linker C, Lesbros C, Gros J, Burrus LW, Rawls A, Marcelle C (2005) $\beta$-catenin-dependent Wnt signalling controls the epithelial organisation of somites through the activation of paraxis. Development 132:3895-3905.

Liu Y, Shi J, Lu C, Wang Z, Lyuksyutova AI, Song X, Zou Y (2005) Rykmediated Wnt repulsion regulates posterior-directed growth of corticospinal tract. Nat Neurosci 8:1151-1159.

Logan CY, Nusse R (2004) The Wnt signaling pathway in development and disease. Annu Rev Cell Dev Biol 20:781-810.

Long JE, Garel S, Depew MJ, Tobet S, Rubenstein JLR (2003) DLX5 regulates development of peripheral and central components of the olfactory system. J Neurosci 23:568-578.

Lyuksyutova AI, Lu CC, Milanesio N, King LA, Guo N, Wang Y, Nathans J, Tessier-Lavigne M, Zou Y (2003) Anterior-posterior guidance af commissural axons by Wnt-frizzled signalling. Science 302:1903-1904.

Maretto S, Cordenonsi M, Dupont S, Braghetta P, Broccoli V, Hassan AB, Volpin D, Bressan G, Piccolo S (2003) Mapping the wnt $/ \beta$-catenin signaling during mouse development and in colorectal tumors. Proc Natl Acad Sci USA, 100:3299-3304.

Maye P, Zheng J, Li L, Wu D (2004) Multiple mechanisms for Wnt11 mediated repression of the canonical Wnt signaling pathway. J Biol Chem 279:24659-24665.

Menezes JR, Luskin MB (1994) Expression of neuron-specific tubulin defines a novel population in the proliferative layers of the developing telencephalon. J Neurosci 14:5399-5416.

Merlo GR, Paleari L, Mantero S, Zerega B, Adamska M, Rinkwitz S, Bober E, Levi G (2002) The Dlx5 homeobox gene is essential for vestibular mor- phogenesis in the mouse embryo through a BMP4-dependent pathway. Dev Biol 248:157-169.

Merlo GR, Mantero S, Zaghetto A, Peretto P, Paina S, Gozzo M (2007) The role of Dlx homeogenes in early development of the olfactory pathway. J Mol Histol, in press.

Mikels AJ, Nusse R (2006) Purified Wnt5a protein activates or inhibits b-catenin-TCF signaling depending on receptor context. PLoS Biol 4:570-582.

Nedelec S, Dubacq C, Trembleau A (2005) Morphological and molecular features of the mammalian olfactory sensory neuron axons: what makes these axons so special? J Neurocytol 34:49-64.

Oishi I, Suzuchi H, Onishi N, Takada R, Kani S, Ohkawara B, Koshida I, Suzuki K, Yamada G, Schwabe GC, Mundlos S, Shibuya H, Takada S, Minami Y (2003) The receptor tyrosine kinase ROR2 is involved in noncanonical Wnt5a/JNK signallng pathway. Genes Cells 8:645-654.

Okabe M, Ikawa M, Kominami K, Nakanishi T, Nishimune Y (1997) "Green mice" as a source of ubiquitous green cells. FEBS Lett 407:313-319.

Puche AC, Poirier F, Hair M, Bartlett PF, Key B (1996) Role of galectin-1 in the developing mouse olfactory system. Dev Biol 179:274-287.

Rugarli E, Ghezzi C, Valsecchi V, Ballabio A (1996) The Kallmann sindrome gene product expressed in COS cells is cleaved on the cell surface to yield a diffusible component. Hum Mol Genet 5:1109-1115.

Scott JW, Brirley T (1999) A functional map in rat olfactory epithelium. Chem Senses 24:679-690.

St John JA, Clarris HJ, Key B (2002) Multiple axon guidance cues establish the olfactory topographic map: how do these cues interact? Int J Dev Biol 46:639-647.

Tarozzo G, Peretto P, Fasolo A (1995) Cell migration from the olfactory placode and the ontogeny of the neuroendocrine compartment. Zool Sci 12:367-383.

Tian Q, Jin H, Cui Y, Guo C, Lu X (2005) Regulation of Wnt gene expression. Development 47:273-281.

Tisay KT, Bartlett PF, Key B (2000) Primary olfactory axons form ectopic glomeruli in mice lacking p75-NTR. J Comp Neurol 428:656-670.

Topol L, Jiang X, Choi H, Garret-Beal L, Carolan PJ, Yang Y (2003) Wnt5a inhibits the canonical Wnt pathway by promoting GSK-3-independent $\beta$-catenin degradation. J Cell Biol 162:899-908.

Torres MA, Yang-Snyder JA, Purcell SM, De Marais AA, McGrew LL, Moon RT (1996) Activities of Wnt-1 class of secreted signalling factors are antagonized by the Wnt-5A class and by a dominant negative cadherin in early Xenopus development. J Cell Biol 133:1123-1137.

Treloar HB, Nurcombe V, Key B (1996) Expression of extracellular matrix molecules in the embryonic rat olfactory pathway. J Neurobiol 31:41-55.

Treloar HB, Tomasiewicz H, Magnuson T, Key B (1997) The central pathway of primary olfactory axons is abnormal in mice lacking the NCAM180 isoform. J Neurobiol 32:643-658.

Tucker KL, Meyer M, Barde YA (2001) Neurotrophins are required for nerve growth during development. Nat Neurosci 4:29-37.

Wang J, Wynshaw-Boris A (2004) The canonical Wnt pathway in early mammalian embryogenesis and stem cell maintenance/differentiation. Curr Opin Genet Dev 14:533-539.

Widelitz R (2005) Wnt signaling through canonical and non-canonical pathways: recent progress. Growth Factors 23:111-116.

Willert K, Jones KA (2006) Wnt signaling: is the party in the nucleus? Genes Dev 20:1394-1404.

Williams-Hogarth LC, Puche AC, Torrey C, Cai X, Song I, Kolodkin AL, Shipley MT, Ronnett GV (2000) Expression of semaphorins in developing and regenerating olfactory epithelium. J Comp Neurosci 423:565-578.

Wray S, Grant P, Gaine H (1989) Evidence that cells expressing luteinizing hormone-releasing hormone mRNA in the mouse are derived from progenitor cells in the olfactory placode. Proc Natl Acad Sci USA 86:8132-8136.

Wu J, Klein TJ, Mlodzik M (2004) Subcellular localization of Frizzled receptors, mediated by their cytoplasmic tails, regulates signaling pathway specificity. PLoS Biol 2:1004-1014.

Yamaguchi TP (2001) Heads or tails: Wnts and anterior-posterior patterning. Curr Biol 11:R713-R724.

Zou Y (2004) Wnt signaling in axon guidance. Trends Neurosci 27:528532. 